\title{
Time-Mean Flow as the Prevailing Contribution to the Poleward Heat Flux across the Southern Flank of the Antarctic Circumpolar Current: A Case Study in the Fawn Trough, Kerguelen Plateau
}

\author{
H. SEKMA AND Y.-H. PARK \\ LOCEAN/MNHN/IPSL, Muséum National d'Histoire Naturelle, Paris, France \\ F. VIVIER \\ LOCEAN/CNRS/IPSL, Université Pierre et Marie Curie, Paris, France
}

(Manuscript received 20 July 2012, in final form 15 November 2012)

\begin{abstract}
The major mechanisms of the oceanic poleward heat flux in the Southern Ocean are still in debate. The long-standing belief stipulates that the poleward heat flux across the Antarctic Circumpolar Current (ACC) is mainly due to mesoscale transient eddies and the cross-stream heat flux by time-mean flow is insignificant. This belief has recently been challenged by several numerical modeling studies, which stress the importance of mean flow for the meridional heat flux in the Southern Ocean. Here, this study analyzes moored current meter data obtained recently in the Fawn Trough, Kerguelen Plateau, to estimate the cross-stream heat flux caused by the time-mean flow and transient eddies. It is shown that the poleward eddy heat flux in this southern part of the ACC is negligible, while that from the mean flow is overwhelming by two orders of magnitude. This is due to the unusual anticlockwise turning of currents with decreasing depth, which is associated with significant bottom upwelling engendered by strong bottom currents flowing over the sloping topography of the trough. The circumpolar implications of these local observations are discussed in terms of the depth-integrated linear vorticity budget, which suggests that the six topographic features along the southern flank of the ACC equivalent to the Fawn Trough case would yield sufficient poleward heat flux to balance the oceanic heat loss in the subpolar region. As eddy activity on the southern flank of the ACC is too weak to transport sufficient heat poleward, the nonequivalent barotropic structure of the mean flow in several topographically constricted passages should accomplish the required task.
\end{abstract}

\section{Introduction}

The poleward oceanic heat flux in the Southern Ocean constitutes an important component of climate, connected with the meridional overturning circulation. The mechanisms by which heat is transported poleward across the strong eastward flow of the Antarctic Circumpolar Current (ACC) are still debated, and this important question has attracted ever increasing interest. In contrast to subtropical regions where the poleward heat flux is largely controlled by the geostrophic mean flow of the western boundary current

Corresponding author address: Young-Hyang Park, LOCEAN/ USM402, Département Milieux et Peuplements Aquatiques, Muséum National d'Histoire Naturelle, 43 Rue Cuvier, F-75231, Paris CEDEX 05, France.

E-mail: yhpark@mnhn.fr system, the quasi-zonal flow of the ACC in the Southern Ocean isolates Antarctica from direct contact with warmer waters from lower latitudes (Rintoul et al. 2001). However, as the subpolar region south of the ACC loses a substantial quantity of heat to the overlying atmosphere ranging from 0.2 to $0.65 \mathrm{PW}\left(1 \mathrm{PW}=10^{15}\right.$ Watts) south of $60^{\circ} \mathrm{S}$ depending on authors (Large and Yeager 2009; Mazloff et al. 2010; Cerovečki et al. 2011; Gordon and Owens 1987; Hastenrath 1982), there should be a compensating poleward oceanic heat flux across the ACC. [As an accurate estimate of heat flux is still in progress (Cerovečki et al. 2011), an intermediate flux value of $0.4 \mathrm{PW}$ will be provisionally adopted here as our reference value.] There are two competing views about how the poleward heat flux occurs, that is, by eddies or by mean flow.

The zonal and time-mean average of meridional heat (or temperature) flux across a latitude circle can be 
written as $\langle\overline{v T}\rangle=\langle\bar{v}\rangle\langle\bar{T}\rangle+\left\langle v^{*} T^{*}\right\rangle+\left\langle\overline{v^{\prime} T^{\prime}}\right\rangle$, where $v$ and $T$ are meridional velocity and temperature, the overbar stands for the time mean, the prime is the deviation from the time mean, the brackets denote the zonal mean, and the star represents the deviation from the zonal mean of time-mean parameters (e.g., Peixoto and Oort 1992; Olbers et al. 2004; Meijers et al. 2007). It is composed of the mean vertical (or overturning) flux $\langle\bar{v}\rangle\langle\bar{T}\rangle$, the mean horizontal (or standing eddy) flux $\left\langle v^{*} T^{*}\right\rangle$, and the transient eddy flux $\left\langle\overline{v^{\prime} T^{\prime}}\right\rangle$. Because of the scarcity of direct observations, the relative importance of these different contributions to the heat flux can only be appreciated from high-resolution numerical models (e.g., Meijers et al. 2007; Volkov et al. 2010; Mazloff et al. 2010). The overturning heat flux, which is mostly determined by the surface Ekman transport, systematically carries heat equatorward across the ACC, with a flux value varying from near $0 \mathrm{PW}$ at $60^{\circ} \mathrm{S}$ to a maximum of $0.8 \mathrm{PW}$ at about $42^{\circ} \mathrm{S}$ (Meijers et al. 2007; Volkov et al. 2010). These northward Ekman fluxes are more than compensated by the combined mean horizontal and transient eddy components to yield net southward heat transports. Although there are some minor differences among models, most of them consistently show that the poleward heat transport across the ACC south of $45^{\circ} \mathrm{S}$ is predominantly carried by the time-mean horizontal circulation and that the heat flux due to transient eddies amounts to approximately one-third of that due to the former (Meijers et al. 2007; Volkov et al. 2010). A notable exception to this is found north of the ACC at around $40^{\circ} \mathrm{S}$, the latitude of several regions of energetic eddies such as the Agulhas Retroflection and the Brazil-Malvinas Confluence, where the contribution of transient processes exceeds that of the mean horizontal flow. In the subpolar region south $60^{\circ} \mathrm{S}$, on the contrary, these models show that the quasi-totality of the poleward heat flux is due to the mean flow with negligible heat flux due to transient eddies. The important contribution of the mean horizontal flow to the poleward heat transport can be explained by the fact that the ACC is not strictly zonal but describes a large-scale north-south meandering with differing mean temperatures. For example, warm waters originating from the Agulhas Retroflection descend gradually southward from the east of the Kerguelen Plateau to Drake Passage where colder waters flow northward along the Argentinian shelf as part of the Malvinas Current, resulting in a net poleward heat transport (Sun and Watts 2002; Volkov et al. 2010).

This Eulerian view is completely different from the streamwise Lagrangian view in which a vertically integrated streamwise coordinate system completely eliminates cross-stream mean heat transport if the flow is perfectly equivalent barotropic (Killworth 1992; Killworth and Hughes 2002). For example, the Lagrangian view emphasizing the predominant role played by eddies stems essentially from a seminal paper of de Szoeke and Levine (1981) who showed no significant cross-stream heat flux by mean geostrophic flow and concluded that eddies must carry most of the heat across the ACC to balance the net oceanic heat loss to the atmosphere at high latitudes. However, deviations from equivalent barotropic flow, as will be shown hereafter, mean that net mean cross-stream heat fluxes can occur.

There have been only a few in situ measurements of eddy heat fluxes, which are mostly concentrated on the northern flank of the ACC (Fig. 1). These include the measurements from moored current meters at the SubAntarctic Front (SAF) south of Australia (Phillips and Rintoul 2000), to the north of the SAF southeast of New Zealand (Bryden and Heath 1985), in the northern Drake Passage (Bryden 1979), across the entire Drake Passage (Nowlin et al. 1985), and at the Polar Front (PF) in Shag Rocks Passage lying between the Malvinas Islands and South Georgia (Walkden et al. 2008). These measurements showed a vertically averaged poleward eddy flux ranging from 10 to $15 \mathrm{~kW} \mathrm{~m}^{-2}$, equivalent to 0.8-1.2 PW when extrapolated over the entire circumpolar extent of $20000 \mathrm{~km}$ and a depth of $4 \mathrm{~km}$. Although this might permit one to claim that observed eddy heat fluxes are more than large enough to balance the heat loss to the atmosphere (Bryden 1979; Phillips and Rintoul 2000; Walkden et al. 2008), these estimates are from the energetic northern flank of the ACC where heat from subtropical basins enters the current, and not from its southern flank where heat should leave the current to be transmitted further poleward to balance the heat loss to the atmosphere south of $60^{\circ} \mathrm{S}$. The latter latitude is close to the circumpolar-mean latitude of the Southern ACC Front (SACCF), which in the South Pacific sector mostly lies south of $60^{\circ} \mathrm{S}$, while that in the South Atlantic and South Indian sectors runs north of $60^{\circ} \mathrm{S}$ (see Fig. 1). In other words, it is the poleward heat flux across the southern flank of the ACC that is most relevant for the heat budget of subpolar regions. Unfortunately, there exists only one case of measurements that meets such a requirement, that is, in the southern part of Drake Passage where Nowlin et al. (1985) reported a vertically averaged poleward eddy heat flux of $0.9 \mathrm{~kW} \mathrm{~m}^{-2}$ or $0.07 \mathrm{PW}$ if extrapolated over the circumpolar section. These values are more than one order of magnitude smaller than those on the northern flank of the ACC and represent only $18 \%$ of the heat loss to the atmosphere south of $60^{\circ} \mathrm{S}$. This is qualitatively consistent with the upper-mentioned model results as well as with the estimation of eddy heat fluxes from floats by Gille (2003) who showed that significant poleward eddy 


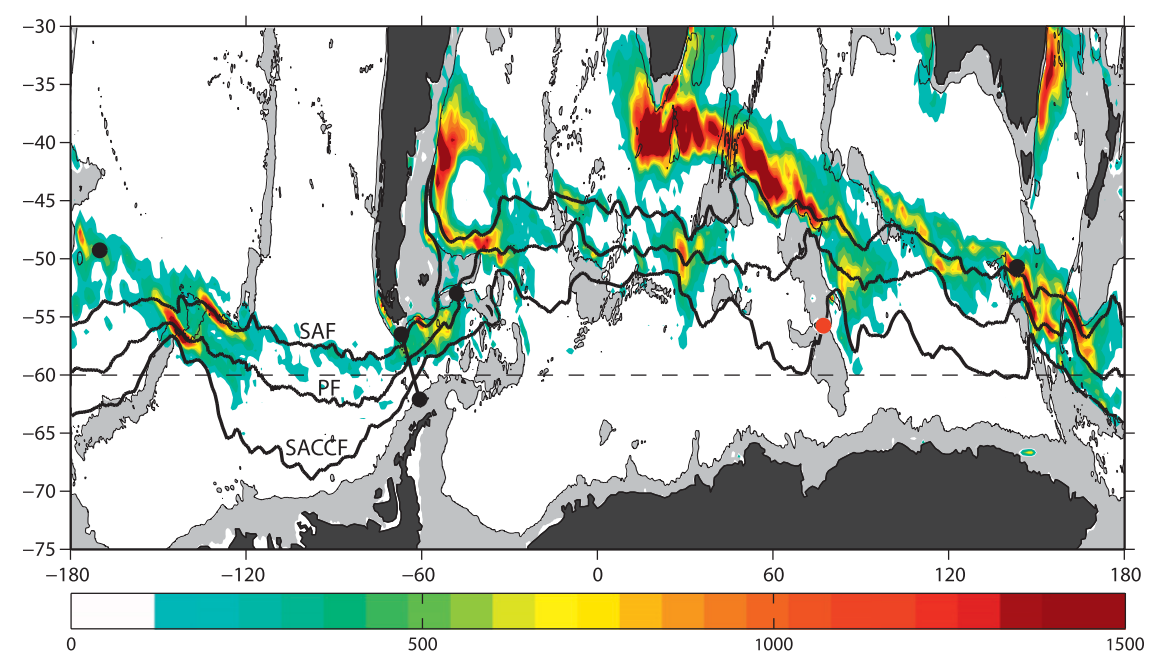

FIG. 1. Positions of historic heat flux observations from current meter moorings (black circles) superimposed on a map of satellite altimetry-derived eddy kinetic energy $\left(\mathrm{cm}^{2} \mathrm{~s}^{-2}\right)$ and three major ACC fronts (thick black curves) adapted from Park et al. (2009). The Drake Passage moorings are shown with a line covering the whole passage and our Fawn Trough mooring site is indicated by a red circle. The submarine topography shallower than $3000 \mathrm{~m}$ is shown gray shaded and the $60^{\circ} \mathrm{S}$ latitude circle is indicated by a dashed line.

heat fluxes are confined along the ACC central stream, while those in its southern half are not statistically different from zero. The latter estimates are also consistent with the very limited poleward eddy flux of $0.04 \mathrm{PW}$ at $60^{\circ} \mathrm{S}$ derived from altimetry by Stammer (1998). These poleward eddy heat flux estimates $(0.04-0.07 \mathrm{PW})$ from observations across the southern flank of the ACC are in great contrast with much higher estimates from high resolution models (Meijers et al. 2007; Treguier et al. 2007). The latter two models both show around 0.1-0.2 PW of poleward eddy heat transport across the ACC in stream-following coordinates at $\sim 60^{\circ} \mathrm{S}$ with approximately equal mean flow contributions.

In this paper we analyze the heat transport across the SACCF from direct measurements of velocity and temperature by three current meter moorings installed during the 2009 Transport Across the Kerguelen Plateau (TRACK) cruise (Park et al. 2009) in the Fawn Trough, a deep passage developed across the Kerguelen Plateau at approximately $56^{\circ} \mathrm{S}$ (red circle in Fig. 1). These measurements may provide us with precious information supplementing the single point observations from the southern part of Drake Passage. Based on a shear (or thermal wind) reference frame, we estimate for the first time the heat flux due to the time-mean flow, in addition to that by transient mesoscale eddies. In previous studies only transient eddy heat fluxes have been estimated from point measurements, without estimating the cross-stream heat flux due to time-mean flow. By contrast, we show here that the eddy heat flux at our site is negligible, as expected from the very weak local eddy activity in this southern part of the ACC, while the contribution from the mean flow is dominant, overwhelming the eddy contribution by two orders of magnitude because of a significant turning of the flow direction with depth. We finally discuss the implications of our point measurements in terms of a zonally integrated heat budget.

\section{Data}

\section{a. Observations}

The Kerguelen Plateau constitutes a major topographic barrier for the eastward-flowing ACC, diverting about two thirds of its total transport to the north of the plateau, with the remaining transport having to pass through the vast area between the Kerguelen Islands and Antarctica (Park et al. 1993). The recent TRACK cruise in the Fawn Trough region (Park et al. 2009) confirmed this and quantified major pathways and transports of the ACC crossing the Kerguelen Plateau (Fig. 2a). It was shown that most of the ACC south of the Kerguelen Islands is tightly channeled into the Fawn Trough (with a sill depth of $\sim 2700 \mathrm{~m}$ centered at $55^{\circ} 50^{\prime} \mathrm{S}, 77^{\circ} 20^{\prime} \mathrm{E}$ ), with a transport of $43 \mathrm{~Sv}\left(1 \mathrm{~Sv} \equiv 10^{6} \mathrm{~m}^{3} \mathrm{~s}^{-1}\right)$ being associated with the SACCF.

As part of the TRACK project, an array of three moorings (M1, M2, and M3) with four current meters on each was deployed across the Fawn Trough during February 2009 and recovered during January 2010 (Fig. 2b). 
(a)

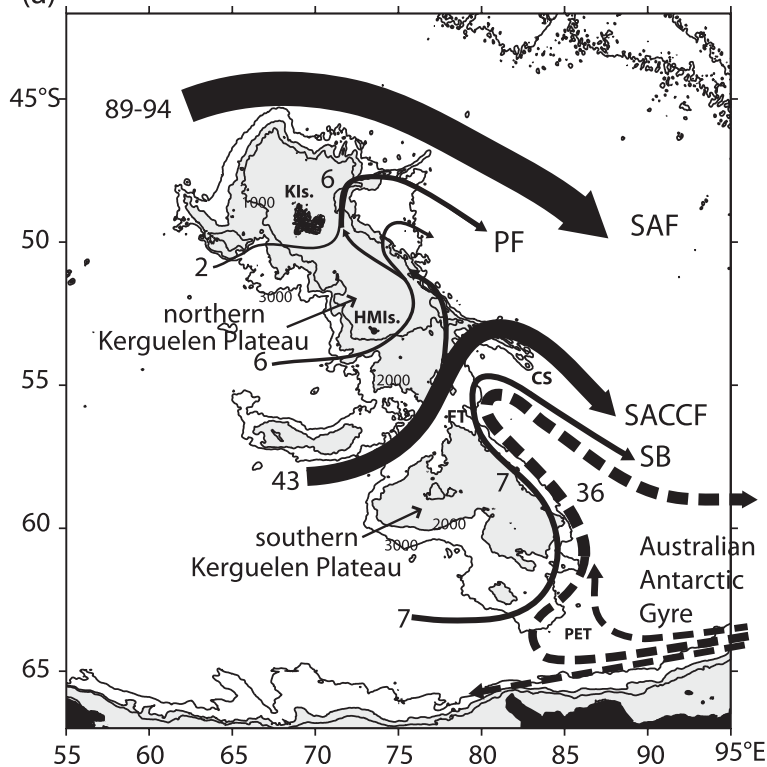

(b)

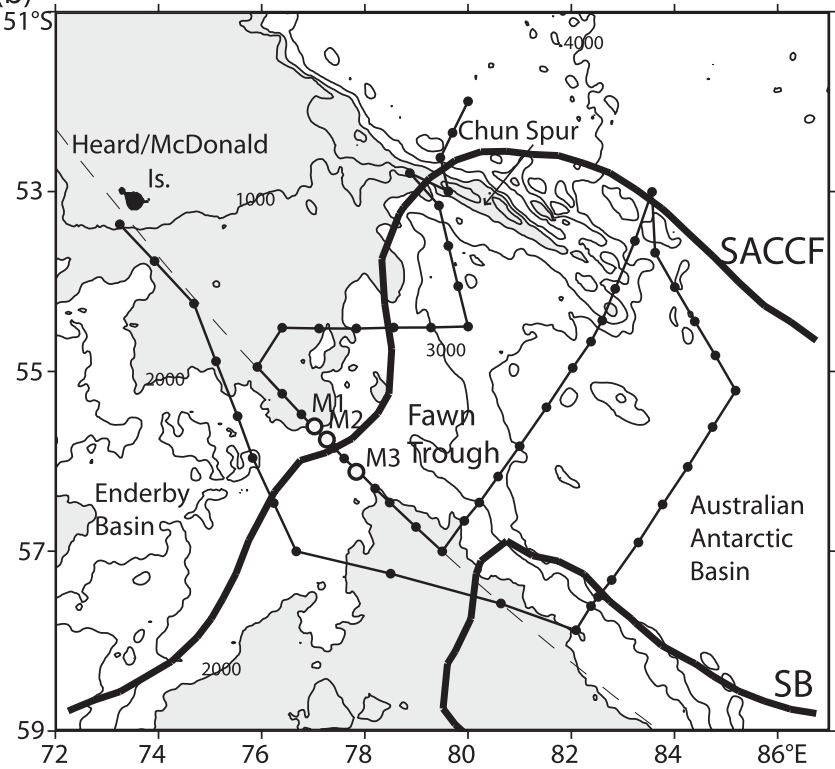

FIG. 2. (a) Different branches of ACC transport crossing the Kerguelen Plateau. The numbers indicate the transport in $\mathrm{Sv}\left(10^{6} \mathrm{~m}^{3} \mathrm{~s}^{-1}\right)$ for the respective branches. (b) The 2009 TRACK cruise plan, with three moorings (unfilled circles: M1, M2, M3) in the Fawn Trough and an array of CTD stations (black dots). Adapted from Park et al. (2009).

Each mooring consisted of one up-looking acoustic Doppler current profiler (ADCP) placed at a few hundred meters below the surface and three Aanderaa current meters between the ADCP and the bottom. In addition, four Microcat conductivity-temperature-depth (CTD) recorders were installed a few meters below each current meter at M2 only. During the deployment and recovery cruises, the entire Fawn Trough region was finely surveyed with top-to-bottom CTD casts together with lowered-ADCP profiles. We used here the records of velocity, temperature, and pressure from current meters as well as more accurate Microcat CTD data at M2. For the up-looking ADCP data, we used those from the deepest bin on each mooring.

The data return rate was approximately $90 \%$. All instruments at M2 ran for the whole deployment period (313 days starting from 25 February 2009), while the other moorings returned records of varying lengths. At M1, two current meters stopped recording before the recovery date (3 January 2010): one at $281 \mathrm{db}$ on 18 December 2009 and the other at $1950 \mathrm{db}$ on 14 November 2009. We have chosen for a later use a common period for all four vertical instruments of this mooring, yielding a net record length of 263 days starting from 25 February 2009. At M3, the current meter at $1226 \mathrm{db}$ stopped functioning on 7 November 2010 and that at $2367 \mathrm{db}$ did not work during the first 3 months. Therefore, a net record length of 177 days starting from 15 May 2010 was retained for this mooring for the subsequent analyses. Finally, raw current, temperature, and salinity data were low-pass filtered using a Gaussian filter (Park and Gambéroni 1995) with a cutoff frequency at $40 \mathrm{~h}$ to suppress inertial, tidal, and higher frequencies and then resampled at hourly intervals.

\section{b. Correction for mooring motion}

Time series measurements of velocity and temperature in the Fawn Trough are contaminated by the vertical excursion of instruments, which does not generally exceed $100 \mathrm{db}$ but can reach up to $450 \mathrm{db}$ during exceptional events with strong current pulses, a feature similar to that observed in the ACC south of Australia (Phillips and Rintoul 2000). We have corrected temperature and velocity data based on the method of Hogg (1986, 1991), which has been used with slight modifications by Cronin and Watts (1996) and Phillips and Rintoul (2000). Briefly, the correction consists of two main steps: temperature correction and velocity correction. The correction method involves a canonical profile of temperature $F$ that can best fit, in a least squares sense, all recorded temperature data with the simple addition of a constant pressure offset $p_{\text {ref }}$ to the $(T, p)$ curves, such as $T(p)=F\left(p-p_{\text {ref }}\right)$. An example of this procedure at M2 is shown in Fig. 3. The corrected temperature $T_{c}$ at the nominal pressure $p_{\text {nom }}$, which is defined as the time-mean pressure at each current meter, can be determined using the canonical profile $F$ and hourly $p_{\text {ref }}$ as 


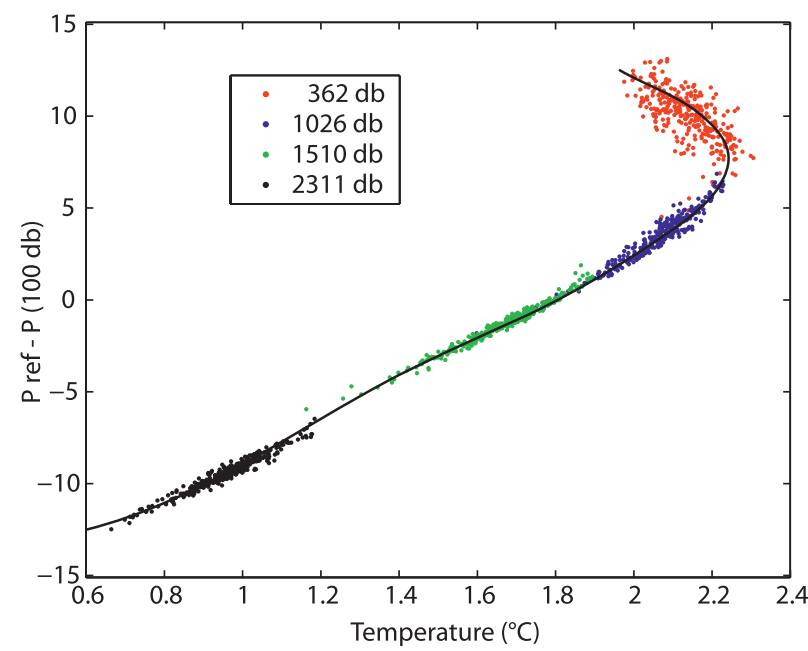

FIG. 3. A canonical profile (black curve) of temperature at M2 as a function of pressure difference $\left(p_{\text {ref }}-p\right)$. Temperature measurements from different current meters are shown in colors. The numbers in the insertion indicate the time-mean depths of the current meters.

$$
T_{c}=F\left(p_{\text {nom }}-p_{\text {ref }}\right)
$$

Assuming a well-defined temperature-salinity $(T-S)$ relationship and based on the thermal wind equations, the method suggests the velocity correction for the $u$ (similarly $v$ ) component as

$$
u_{c}=\frac{u_{u}-u_{l}}{T_{u}-T_{l}}\left(T_{c}-T_{l}\right)+u_{l},
$$

where the subscripts $c, u$, and $l$ refer to the corrected parameter and the upper and lower instrument levels, respectively. Equation (2) implies a linear relationship between the velocity difference and the temperature difference within the layer between the upper and lower instrument levels.

We have successfully applied the correction method to the temperature and velocity data from the moorings. The method failed, however, for the uppermost current meters at M1 and M2 for which the denominator in the right hand side of (2), $T_{u}-T_{l}$, often approaches zero. As can be seen in Fig. 3, this feature is related to the existence of the temperature maximum (Tmax) layer found between the upper two current meters, which is in turn induced by the presence of the subsurface temperature minimum layer or Winter Water (not shown) found generally at around 200- to 100-m depth (from the north to the south), a unique characteristic of the Antarctic zone (e.g., Park et al. 1998). To overcome this difficulty, we propose a new formula for the velocity correction by replacing temperature $T$ in (2) by in situ density $\rho$, such as

$$
u_{c}=\frac{u_{u}-u_{l}}{\rho_{u}-\rho_{l}}\left(\rho_{c}-\rho_{l}\right)+u_{l},
$$

where $\rho_{c}$ can be determined in a similar fashion to (2) for the temperature, by first searching for the canonical profile of density $\rho(p)=G\left(p-p_{\text {ref }}\right)$ and then calculating the corrected density as $\rho_{c}=G\left(p_{\text {nom }}-p_{\text {ref }}\right)$. This new Eq. (3) is theoretically superior to (2) because it does not require the hypothesis of a well-defined $T-S$ relationship, which is difficult to justify in the subsurface layer of the Antarctic zone. However, its application is limited by the availability of salinity data, and thus here restricted to M2. No correction is applied to the uppermost current meter at M1. This, however, has limited impact because of comparatively weak currents and small vertical excursions of the instrument (mean $=10$ $\mathrm{db}$; $\max =60 \mathrm{db}$ ). For M2, the new Eq. (3) has been applied to all four current meters and the resulting corrections are compared with those using (2), an example of which for the current meter at $1026 \mathrm{db}$ is shown in Fig. 4. For weak vertical displacements $(<100 \mathrm{db})$ of the instrument, there appears no significant difference in correction between the two formulae, which is the general case, however, in a few cases of strong displacements $(>150 \mathrm{db})$ the difference can be important reaching up to $5 \mathrm{~cm} \mathrm{~s}^{-1}$. For the lower current meters, the difference is much smaller $\left(<2 \mathrm{~cm} \mathrm{~s}^{-1}\right)$. The resulting corrected time series of temperature and velocity on all three moorings are shown in Fig. 5. These form the basis of the subsequent analyses.

\section{Vertical structure of velocity and temperature}

\section{a. Vertical structure of time-mean velocity and temperature}

To locate the vertical and horizontal positions of each current meter relative to the frontal structure of temperature across the Fawn Trough, Fig. 6 shows the observed time-mean currents and velocity variance ellipses, which are superimposed on a temperature section drawn from the top-to-bottom CTD data gathered during the deployment and recovery TRACK cruises. According to the circumpolar analysis of the ACC fronts from altimetry as well as the regional analysis of historical hydrographic, float, and animal-borne data (Park et al. 2009, 2008; Roquet et al. 2009), the SACCF can be best located at the deepest $(\sim 2700 \mathrm{~m})$ part of the trough centered at $55.9^{\circ} \mathrm{S}$. Mooring M2, revealing the strongest mean flow ( $36 \mathrm{~cm} \mathrm{~s}^{-1}$ at $362 \mathrm{db}$ ), is located very close to the SACCF axis, while M1 and M3 are near the northern and southern edges of the front. The vertical velocity structure at M1 and M2, located on the northern flank of 


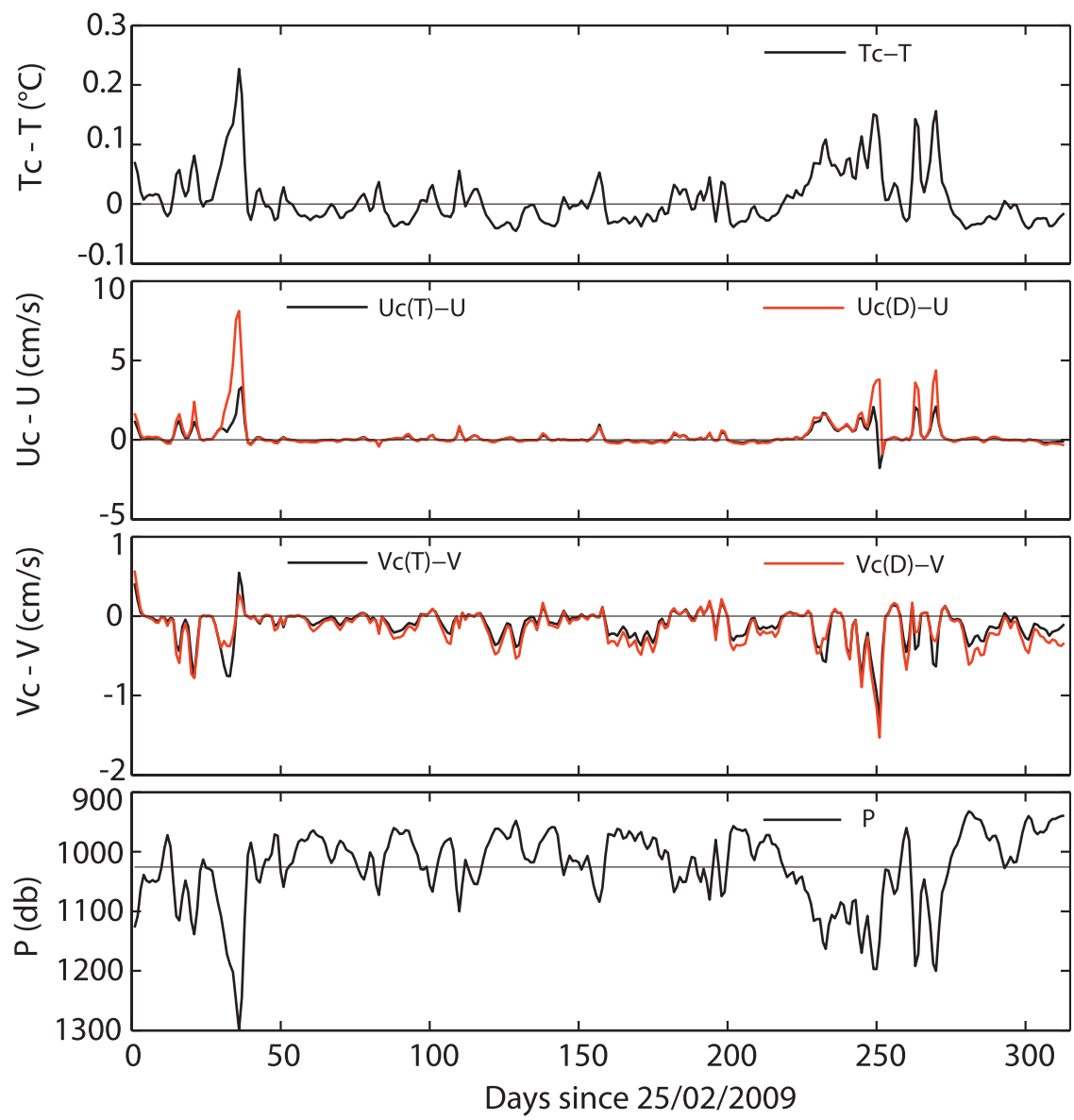

FIG. 4. Corrections in (top) temperature and velocity-(second row) $u$ and (third row) $v$-applied to the current meter data at $1026 \mathrm{db}$ at M2. For the correction in velocity, results from two formulae are compared: red curves from (3) and black curves from (2). (bottom) The instrument pressure fluctuations and the horizontal line represents the record-length mean pressure or $p_{\text {nom }}$.

the trough, reveals some similarity. The dominant flow direction is to the northeast at both sites, roughly aligned with the trough axis, and the flow speed gradually decreases toward the bottom, displaying a predominantly self-similar vertical structure except for the near-bottom layer. This suggests a concentration of the eastward flow to the northern flank of the Fawn Trough. Note also that for both moorings, upper instruments straddle the Tmax layer.

By contrast, the southernmost mooring M3, located on the southern flank of the trough, holds all its four current meters below the Tmax layer. It reveals a flow direction far different from the two northern ones: eastward at $530 \mathrm{db}$ but gradually turning to the south with increasing depth, thus showing the clearest evidence of the nonequivalent barotropic structure. Moreover, the mean flow speed does not monotonically decrease toward the bottom but a minimum is found at a middepth of $1226 \mathrm{db}$, below which it increases slightly toward the bottom.

Also noticeable are the relatively strong near-bottom currents, especially at M2 $\left(14 \mathrm{~cm} \mathrm{~s}^{-1}\right)$ and M3 $\left(12 \mathrm{~cm} \mathrm{~s}^{-1}\right)$, which have important implications for generating significant bottom upwelling over a sloping topography, as will be discussed later. Mean and variance of the temperature and velocity fields are provided in Table 1 , together with the kinetic energy. Compared to the relatively strong mean currents, transient currents are very weak, consistent with Fig. 1. For example, the ratio between the eddy kinetic energy (EKE) and the mean kinetic energy (MKE), EKE/MKE, is mostly less than 0.1 for the current meters at M1 and M2 and around a mean of 0.35 at M3. These values are far below those observed in the energetic northern flank of the ACC where the ratio is close to the unity (e.g., Bryden and Heath 1985; Phillips and Rintoul 2000). This weak EKE 

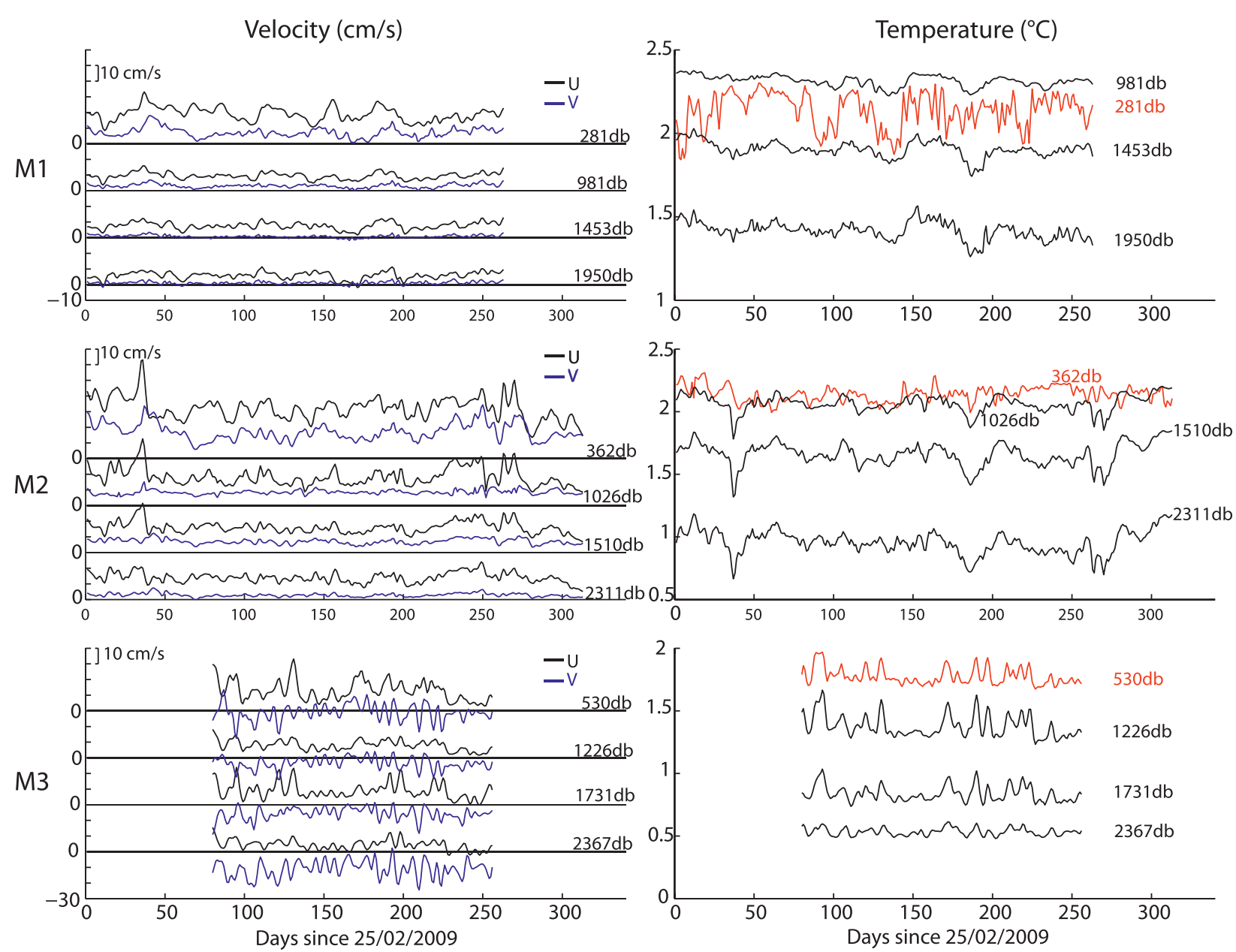

FIG. 5. Time series of mooring motion-corrected velocity and temperature on (top to bottom) the three moorings. (left) The east (north) component of velocity is shown in black (blue), and (right) the temperature at the uppermost current meter on each mooring is shown in red, for clarity.

from the moored current meters is further supported by a local analysis of altimeter data for 2009 (not shown), which reveals a steady current axis and the weakest annual mean EKE at and immediately downstream of the moorings.

\section{b. Spatial coherency of time-variable velocity and temperature}

At both M1 and M2, the temperature variations at the uppermost current meter (281 db for M1;362 db for M2) are not significantly correlated $(r \sim 0.13)$ with those at the lower current meters $(981,1453$, and $1950 \mathrm{db}$ at $\mathrm{M} 1 ; 1026,1510$, and $2311 \mathrm{db}$ at M2), while the latter are highly correlated among them $(r \sim 0.9)$. This suggests that the temperature variability of the Antarctic Surface Water found above the Tmax layer is disconnected from that of the Circumpolar Deep Water that is found below the Tmax layer. At M3 where all four current meters are located below the Tmax layer, the temperature variations are significantly correlated $(r=0.6-0.93)$ throughout the water column. These features are also evident from a simple inspection of temperature time series (see Fig. 5). Horizontally, the temperature variations below the Tmax layer at M1 and M2 are significantly correlated $(r \sim 0.65)$, while those in the surface layer are not $(r=-0.06)$. Between M2 and M3, no significant correlation is observed throughout the water column.

The velocity variations on all three moorings are significantly correlated vertically $(r=0.4-0.9)$, with higher (lower) correlations between the adjacent (far-field) instruments. Somewhat similar to the case of temperature, the velocity variations at M1 and M2 are significantly correlated horizontally $(r \sim 0.55)$ except for the uppermost instruments $(r=-0.29)$, while those at M2 and M3 show no significant correlations $(r \sim-0.16)$, apart from a marginal correlation $(r=-0.4)$ for the uppermost instruments. 


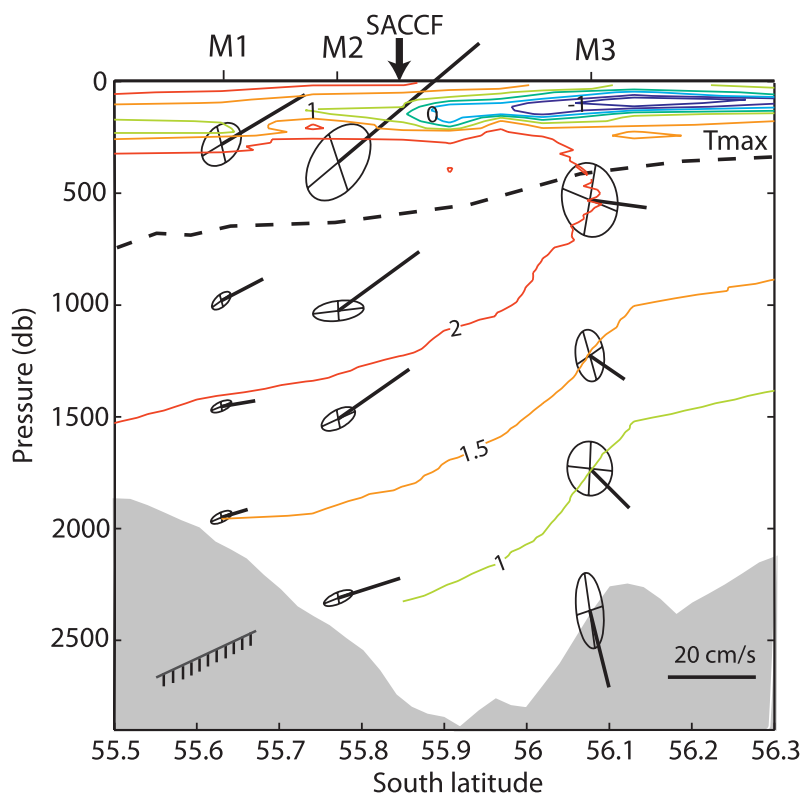

FIG. 6. Time-mean velocity vectors and velocity variance ellipses on the three moorings superimposed on the temperature section across the Fawn Trough. The Tmax layer and the approximate position of the SACCF are indicated. Also shown in the bottomleft (right) corner of the figure is the trough axis (velocity scale).

In summary, there appears no significant correlation in temperature variability between the surface layer above the Tmax layer and the deeper layer below. Also, while the parameter variations are relatively well correlated horizontally between moorings $\mathrm{M} 1$ and $\mathrm{M} 2$, they are not so between M2 and M3, suggesting two independent flow regimes. The dominant vertical modes of variability in velocity on the northern flank of the Fawn Trough can be examined by an empirical orthogonal function (EOF) decomposition of velocity at M2 (Fig. 7). (The EOF decomposition at M1 reveals a similar pattern.)
The first mode explaining $53 \%$ of the total variance shows a vertical structure that is approximately equivalent barotropic (or vertically self-similar), while the second $(27 \%)$ and third (14\%) modes are clearly nonequivalent barotropic, with an abrupt change in flow direction across the Tmax layer. For comparison, the first three EOFs at M3 explain 59\%, 28\%, and 6\% of the total variance, respectively, with the clearest evidence for an equivalent (nonequivalent) barotropic structure being observed in the first (third) mode. These modes appear qualitatively as a combination of a barotropic mode and a first baroclinic mode. The percentage $(53 \%-$ $59 \%$ ) of the equivalent barotropic structure in the Fawn Trough is similar to that observed in the Malvinas Current flowing over a sloping shelf (Vivier and Provost 1999) but is much less than that ( $90 \%)$ observed in the nearly flat-bottomed Yaghan Basin of northern Drake Passage (Ferrari et al. 2012). This is not surprising, however, because a strong current-topography interaction can generate significant baroclinic modes.

\section{Heat fluxes across the SACCF in the Fawn Trough}

\section{a. Eddy time scales and reference frames}

For evaluating cross-stream eddy heat fluxes, it is of utmost importance to determine the most adequate coordinate system and time scales (see in particular the careful discussion by Nowlin et al. 1985). To isolate the mesoscale variations from short tidal and inertial periods on the one hand, and longer periods associated with lateral shifts of the frontal structure of currents and a seasonal effect on the other hand, Nowlin et al. (1985) proposed a bandpass width of $40 \mathrm{~h}$ to 90 days as the correct eddy time scales. This bandpass width has now been commonly accepted (e.g., Phillips and Rintoul

TABLE 1. Temperature and velocity statistics on the three moorings in the Fawn Trough. Eddy kinetic energy (EKE) and mean kinetic energy $(\mathrm{MKE})$ are given as $\mathrm{EKE}=\left(\overline{u^{\prime 2}}+\overline{v^{\prime 2}}\right) / 2$; MKE $=\left(\bar{u}^{2}+\bar{v}^{2}\right) / 2$.

\begin{tabular}{|c|c|c|c|c|c|c|c|c|c|c|c|}
\hline & $\begin{array}{l}\text { Pressure } \\
\text { (dbar) }\end{array}$ & $\begin{array}{l}\text { Record length } \\
\text { (days) }\end{array}$ & $\bar{T}\left({ }^{\circ} \mathrm{C}\right)$ & $\bar{u}\left(\mathrm{~cm} \mathrm{~s}^{-1}\right)$ & $\bar{v}\left(\mathrm{~cm} \mathrm{~s}^{-1}\right)$ & $\overline{T^{\prime 2}}\left({ }^{\circ} \mathrm{C}^{2}\right)$ & $\overline{u^{\prime 2}}\left(\mathrm{~cm}^{2} \mathrm{~s}^{-2}\right)$ & $\overline{v^{\prime 2}}\left(\mathrm{~cm}^{2} \mathrm{~s}^{-2}\right)$ & $\operatorname{EKE}\left(\mathrm{cm}^{2} \mathrm{~s}^{-2}\right)$ & $\operatorname{MKE}\left(\mathrm{cm}^{2} \mathrm{~s}^{-2}\right)$ & $\frac{\mathrm{EKE}}{\mathrm{MKE}}$ \\
\hline \multirow[t]{4}{*}{ M1 } & 281 & 263 & 2.14 & 18.98 & 7.17 & 0.011 & 20.00 & 9.62 & 14.81 & 205.78 & 0.07 \\
\hline & 981 & 263 & 2.31 & 9.50 & 3.16 & 0.001 & 4.61 & 1.66 & 3.14 & 50.09 & 0.06 \\
\hline & 1453 & 263 & 1.91 & 7.67 & 0.80 & 0.002 & 5.39 & 0.79 & 3.09 & 29.77 & 0.10 \\
\hline & 1950 & 263 & 1.42 & 5.96 & 1.14 & 0.003 & 5.63 & 0.89 & 3.26 & 18.41 & 0.18 \\
\hline \multirow[t]{4}{*}{ M2 } & 362 & 313 & 2.14 & 32.04 & 17.19 & 0.004 & 53.51 & 30.32 & 41.91 & 660.96 & 0.06 \\
\hline & 1026 & 313 & 2.07 & 18.40 & 8.54 & 0.005 & 33.21 & 2.25 & 17.73 & 205.75 & 0.09 \\
\hline & 1510 & 313 & 1.66 & 16.13 & 7.16 & 0.009 & 14.67 & 2.94 & 8.81 & 155.71 & 0.06 \\
\hline & 2311 & 313 & 0.96 & 14.05 & 2.85 & 0.009 & 10.77 & 1.35 & 6.06 & 102.78 & 0.06 \\
\hline \multirow[t]{4}{*}{ M3 } & 530 & 177 & 1.78 & 12.94 & -1.12 & 0.004 & 40.37 & 28.33 & 34.35 & 84.30 & 0.41 \\
\hline & 1226 & 177 & 1.38 & 7.94 & -3.44 & 0.008 & 10.73 & 13.88 & 12.31 & 37.43 & 0.33 \\
\hline & 1731 & 177 & 0.84 & 8.99 & -5.71 & 0.004 & 26.14 & 15.18 & 20.66 & 56.69 & 0.36 \\
\hline & 2367 & 177 & 0.53 & 4.35 & -11.06 & 0.001 & 10.17 & 29.63 & 19.90 & 70.59 & 0.28 \\
\hline
\end{tabular}




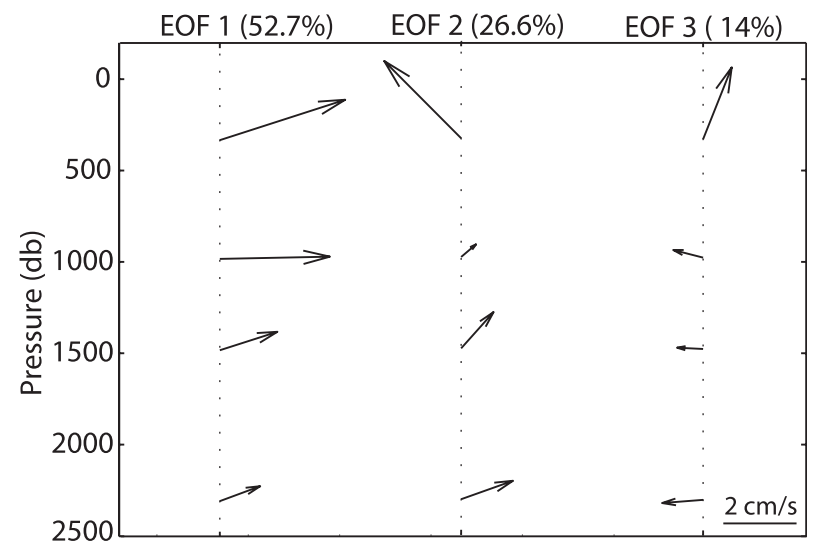

FIG. 7. The first three empirical orthogonal functions (EOFs) of current variations at M2.

2000; Walkden et al. 2008) and is adopted as well in the present study.

Concerning the reference frame by which the direction of along-stream or cross-stream is determined, there are two kinds of coordinate systems: time-invariant and time-varying systems. The time-invariant coordinate system is sometimes called geographic coordinate system in which we define along-stream as being directed along the time-mean flow (Bryden 1979) and cross-stream is $90^{\circ}$ to the left of along-stream. There are two varieties of time-varying coordinate systems. The first one, proposed by Nowlin et al. (1985), is based on a mean flow with slowly varying direction, derived from the 90-day low-passed velocity. The cross-stream velocity is defined to be positive to the left of the 90-day low-passed direction. This frame will be referred to as the 90d-LP coordinate system hereinafter.

The second time-varying coordinate system, used for instance by Phillips and Rintoul (2000), is referred to as shear coordinate system, which defines along-stream as the daily-averaged direction of the vertical current shear between two chosen levels, and cross-stream is $90^{\circ}$ to the left of along-stream. This coordinate system, which was first employed by Hall $(1986,1989)$ in her analyses of the Gulf Stream and Kuroshio, bears both strengths and weaknesses. As emphasized by Phillips and Rintoul (2000), the strong point resides in the fact that the alongstream coordinate corresponds to the direction of the thermal wind, which we will usefully exploit below in terms of thermal advection in the water column. The weakness lies in the arbitrary choice of two levels from which the thermal wind is determined. In the uppermentioned works these levels were chosen in the upper layer for one and in the deeper layer for the other. By contrast, we define a vertical shear between each pair of adjacent levels, rather than between arbitrarily chosen levels, because the magnitude and direction of the thermal wind are not constant in the water column but change significantly with depth, at least in our case.

\section{$b$. Thermal wind and temperature advection in the shear coordinate system}

As we will use the shear method as our principal means of determination of poleward heat fluxes by timemean flow at our site, it may be instructive to briefly review the relationship between the thermal wind and associated temperature advection. Using the geostrophic and hydrostatic balance equations, the thermal wind equations can be written as (Bryden 1976):

$$
\left(\frac{\partial u}{\partial z}, \frac{\partial v}{\partial z}\right)=\left(b \frac{\partial \rho}{\partial y},-b \frac{\partial \rho}{\partial x}\right), \text { with } \quad b=\frac{g}{\rho_{0} f}
$$

where $\rho$ is density with its representative value of $\rho_{0}$, $g$ is gravity, and $f$ is the Coriolis parameter. Assuming a well-defined relationship between temperature and salinity, which holds for our CTD data except for the surface layer above the Tmax layer, density can be expressed as a function of temperature alone, such as (Bryden 1976):

$d \rho=\frac{\partial \rho}{\partial T} d T+\frac{\partial \rho}{\partial S} d S=-\left(\alpha-\beta \frac{d S}{d T}\right) d T=-\alpha_{e} d T$,

where $\alpha=-\partial \rho / \partial T$ is a thermal expansion coefficient, $\beta=\partial \rho / \partial S$ is a haline contraction coefficient, and $\alpha_{e}=$ $\alpha-\beta d S / d T$ is an effective thermal expansion coefficient. This allows the thermal wind Eq. (4) to be written in terms of horizontal temperature gradient:

$$
\left(\frac{\partial u}{\partial z}, \frac{\partial v}{\partial z}\right)=\left(-c \frac{\partial T}{\partial y}, c \frac{\partial T}{\partial x}\right), \quad \text { with } \quad c=\frac{\alpha_{e} g}{\rho_{0} f} .
$$

The thermal wind $\mathbf{V}_{T}$, which is the difference of velocity vectors between the upper and lower levels $\mathbf{V}_{T}\left(u_{u}-u_{l}, v_{u}-v_{l}\right)$, can then be expressed in vector notation as

$$
\mathbf{V}_{\mathrm{T}}=c \Delta z \mathbf{k} \times \nabla \bar{T}
$$

where $\mathbf{k}$ is the unit vector in vertical direction, and $\Delta z$ is the layer thickness between the two levels, and $\nabla \bar{T}$ is the mean horizontal gradient of temperature of the layer. Equation (7) shows that the thermal wind is parallel to mean isotherms, with cold (warm) water being located to the right (left) of the thermal wind direction in the Southern Hemisphere. As individual velocity vectors at each level are generally not parallel to the mean isotherms of the layer, there arises advection of warm or 
(a) Warm Advection

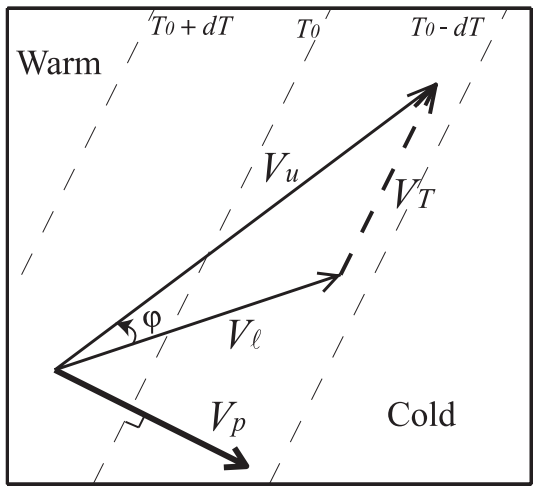

(b) Cold Advection

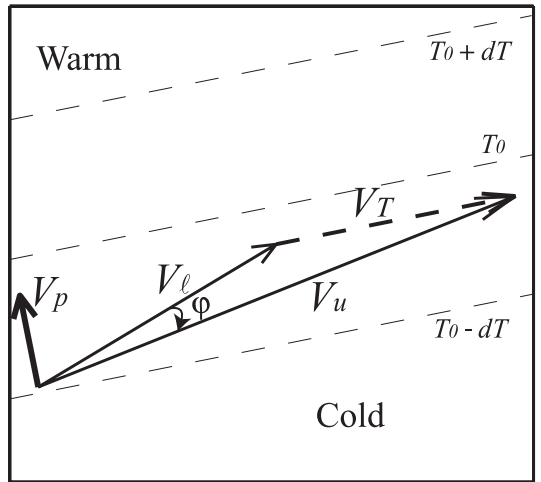

(c) No Thermal Advection

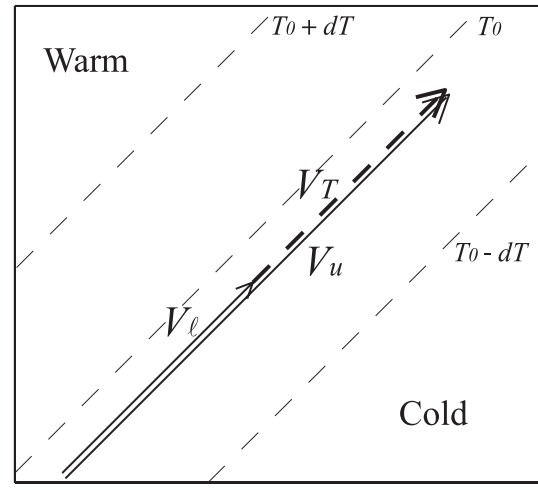

FIG. 8. Schematics showing the relation between the thermal wind $\mathbf{V}_{T}$, defined as a velocity shear between the upper ( $\left.\mathbf{V}_{u}\right)$ and lower layer $\left(\mathbf{V}_{l}\right)$, and (a)-(c) temperature advection in the Southern Hemisphere. The $\mathbf{V} p$ is the velocity component perpendicular to the thermal wind.

cold water depending on the sense of turning of velocity vectors with decreasing depth (Fig. 8). Anticlockwise (clockwise) turning is associated with warm (cold) advection (Figs. 8a,b), and no thermal advection occurs when the currents at both levels are parallel (Fig. 8c). It can also be shown that warm (cold) advection in turn is associated with upwelling (downwelling) (Bryden 1976; Phillips and Rintoul 2000; see also the section 4e below).

In the shear coordinate system along-stream coincides with the direction of the thermal wind while the crossstreamflow (shown as $\mathbf{V}_{p}$ in Fig. 8) is perpendicular to isotherms such that the poleward (equatorward) heat flux is associated with warm (cold) advection. If we apply this theoretical consideration to the progressive vector diagrams from the three current meter moorings in the Fawn Trough (Fig. 9), it is not difficult to recognize the prevailing warm advection (and upwelling) over the entire water column at the southernmost site M3 where the vertical structure of the mean flow is highly nonequivalent barotropic, with the anticlockwise turning of velocity vectors with decreasing depth. At M1 and M2, noticeable warm advection is also evident at a deep layer (981-1453 db at M1, 1510-2311 db at M2), while there is indication of minor cold advection (or downwelling) in the near-bottom layer (1453-1950 db) at M1. On the other hand, no significant turning of currents (thus no significant thermal advection) is seen in the 1026-1510 db layer at M2 where velocity vectors at both levels are nearly parallel, which corresponds to the equivalent barotropic mode. A more quantitative evaluation of the poleward heat flux is given below.

\section{c. Estimation of poleward heat flux by transient eddies}

The calculation procedures of eddy heat flux at M2 relative to each reference frame are shown graphically in Fig. 10. The daily time series of temperature and velocity used here have previously been low-pass filtered at $40 \mathrm{~h}$ using a Gaussian filter (Park and Gambéroni 1995), as mentioned previously. For the time-invariant geographical coordinate system, the cross-stream velocity time series $V(t)$ is obtained as

$$
V(t)=v(t) \cos \varphi-u(t) \sin \varphi,
$$

where $\varphi=\tan ^{-1}(\bar{v} / \bar{u})$ is the angle of the time-mean current direction relative to the positive $x$-coordinate (east). Low-frequency variations of periods greater than
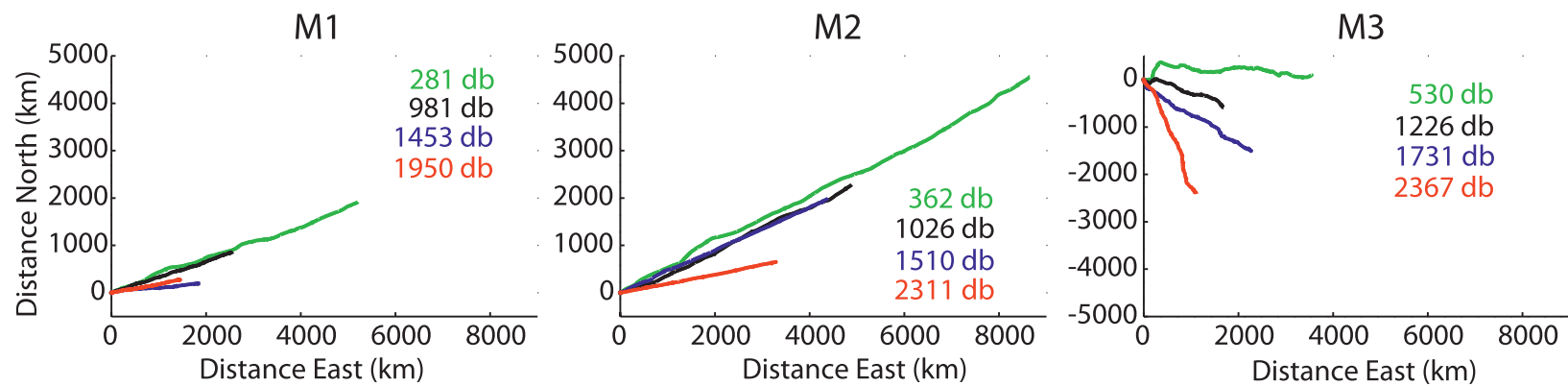

FIG. 9. Progressive vector diagrams at different pressures on (left to right) the three moorings. 
(a) Geographic

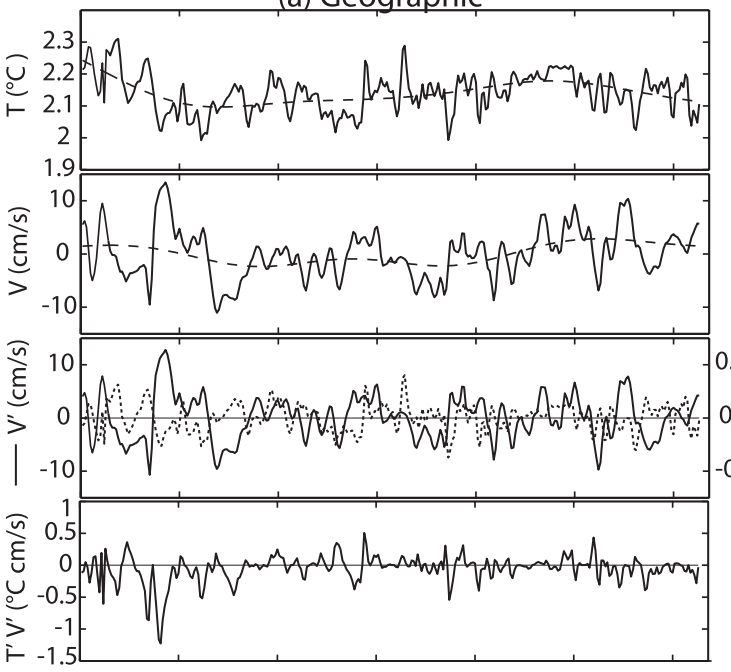

(b) $90 \mathrm{~d}-\mathrm{LP}$
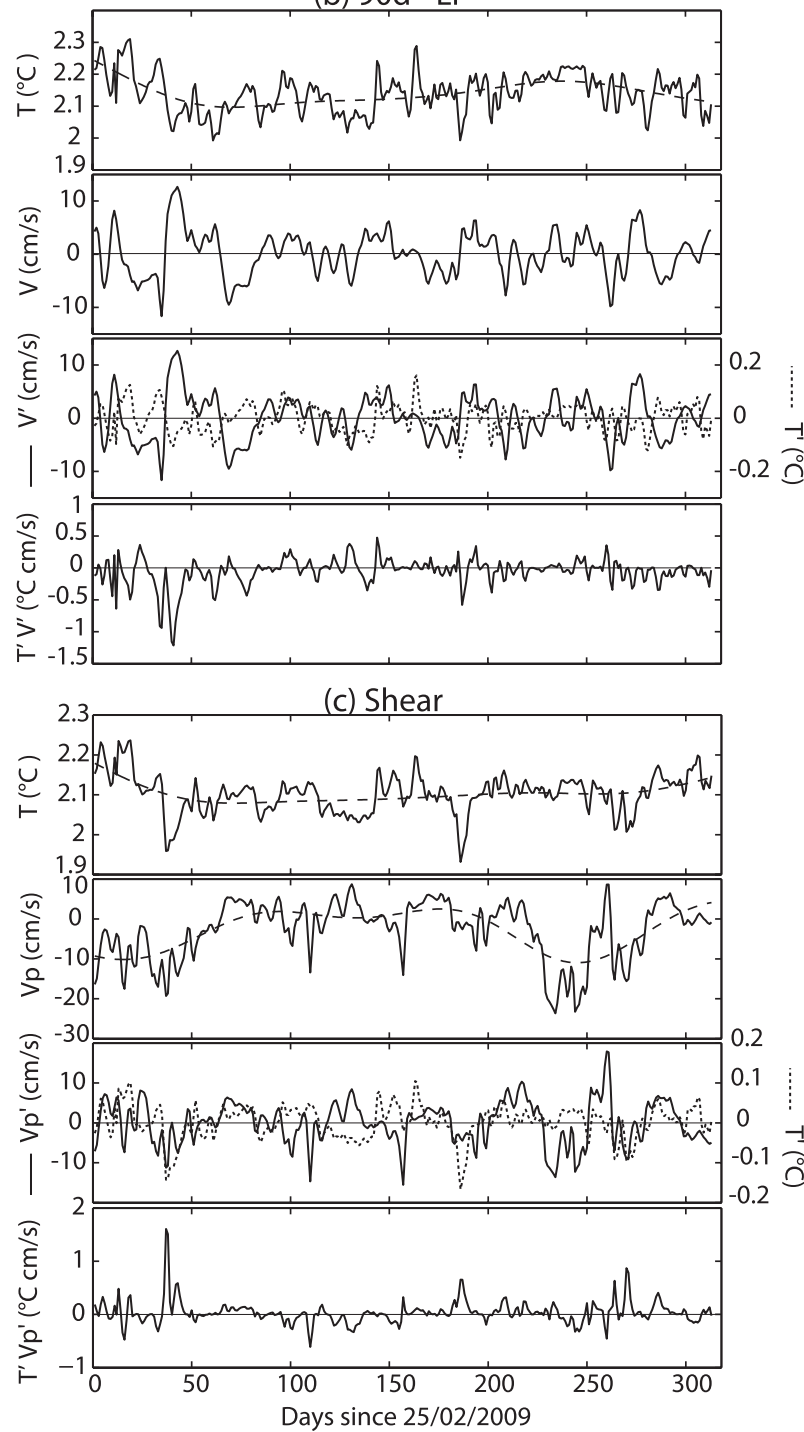

90 days (dashed lines in Fig. 10a) are filtered out from the daily time series using the upper-mentioned Gaussian filter to retain mesoscale anomaly time series, $T^{\prime}(t)$ and $V^{\prime}(t)$, having periods between $40 \mathrm{~h}$ and 90 days. This yields the correlation time series of the two parameters $V^{\prime} T^{\prime}$. The mean eddy heat flux $\overline{Q^{\prime}}$ is then obtained by using (e.g., Nowlin et al. 1985; Phillips and Rintoul 2000):

$$
\overline{Q^{\prime}}=\rho_{0} C_{p} \overline{V^{\prime} T^{\prime}}=41.4 \overline{V^{\prime} T^{\prime}}\left(\mathrm{kW} \mathrm{m}^{-2}\right),
$$

where the overbar denotes the record-length mean, $\rho_{0}=$ $1035 \mathrm{~kg} \mathrm{~m}^{-3}, C_{p} \approx 4000 \mathrm{~J} \mathrm{~kg}^{-1}{ }^{\circ} \mathrm{C}^{-1}$ is the specific heat at constant pressure, and $\overline{V^{\prime} T^{\prime}}$ has been calculated in units of ${ }^{\circ} \mathrm{C} \mathrm{cm} \mathrm{s}^{-1}$. The resulting eddy heat fluxes at different levels at the three moorings are shown in the third column of Table 2. Similar procedures are applied to the 90d-LP coordinate system (Fig. 10b), except for $\varphi$ in (8), which is instead defined as the time-varying daily angles of the 90d-LP velocity vectors relative to the positive $x$-coordinate. The corresponding eddy heat fluxes are shown in the fourth column of Table 2. For the shear coordinate system, the cross-stream velocity time series $V_{p}(t)$ is calculated as the velocity component perpendicular to the daily direction of the vertical current shear between adjacent levels (see Fig. 8). This yields a common time series for adjacent levels, which is thus assigned to the midway of these levels. The corresponding layer-mean temperature time series is obtained by averaging those from the upper and lower levels, such as $T(t)=\left[T_{u}(t)+T_{l}(t)\right] / 2$. The other procedures for calculating $T^{\prime}(t)$ and $V_{p}^{\prime}(t)$ are same as those for the geographical coordinate system (Fig. 10c). The resulting eddy heat fluxes are given at the midway of adjacent levels in the fifth column of Table 2.

The statistical significance of time-mean eddy heat fluxes is tested following the method employed by Nowlin et al. (1985). Briefly, for testing zero correlation at a $95 \%$ confidence level, the method compares the zero lag cross correlation between $V^{\prime}(t)$ and $T^{\prime}(t)$ with its standard error SE multiplied by 2 . The latter is determined by the number of degrees of freedom $N^{*}$, such as $\mathrm{SE}=1 / \sqrt{N^{*}}$, which is in turn determined by the

FIG. 10. A typical example at M2, illustrating (top to bottom in each series) how to get mesoscale eddy time series of temperature $T^{\prime}$ and cross-stream velocity $V^{\prime}$ to obtain their product $T^{\prime} V^{\prime}$ in three different coordinates: (a) geographic, (b) 90d-LP, (c) shear. Initial temperature $(T)$ and velocity $(V)$ time series have previously been low-pass filtered at $40 \mathrm{~h}$, from which the 90-day low-passfiltered series (dashed lines superimposed on the $T$ and $V$ curves) are subtracted to get the bandpass (40 h-90 days) filtered $T^{\prime}$ and $V^{\prime}$. See the text for details. 
TABLE 2. Estimates of heat flux $\left(\mathrm{kW} \mathrm{m}^{-2}\right)$ on the three moorings. Eddy heat fluxes are estimated in three different coordinates (geographic, 90d-LP, shear), while heat fluxes due to mean flow are in shear coordinates. Significant fluxes at a $95 \%$ confidence level are shown boldfaced. For mean heat flux estimates, error bars are given as \pm the standard error.

\begin{tabular}{|c|c|c|c|c|c|}
\hline & Pressure & Eddy & Heat Fl & & Mean Hea \\
\hline & $(\mathrm{db})$ & Geographic & $\begin{array}{l}\text { 90d- } \\
\text { LP }\end{array}$ & Shear & Shear \\
\hline$M$ & 281 & 0.10 & 0.21 & & $-84.8 \pm 24.7$ \\
\hline & 981 & -0.23 & -0.25 & $\begin{array}{l}0.24 \\
1.61\end{array}$ & $\begin{array}{r}-84.0 \pm 24 . \\
-489.0 \pm 18.5\end{array}$ \\
\hline & 1454 & -0.35 & -0.39 & 1.61 & $164.9 \pm 31.4$ \\
\hline & 1950 & -0.22 & -0.20 & & \\
\hline M2 & 362 & -2.35 & -2.38 & & $-248.4 \pm 138.5$ \\
\hline & 1026 & 1.03 & 0.82 & $\begin{array}{r}1.42 \\
-3.50\end{array}$ & $-211.4 \pm 178.9$ \\
\hline & 1510 & 0.41 & 0.38 & $\begin{array}{l}-3.50 \\
0.32\end{array}$ & $-611.7 \pm 12.2$ \\
\hline & 2311 & -0.68 & -0.69 & & $-611.7 \pm 12.2$ \\
\hline M3 & 532 & -0.58 & -0.65 & -2.40 & $-368.7 \pm 27.1$ \\
\hline & 1228 & -1.80 & -1.81 & $\begin{array}{r}2.40 \\
2.28\end{array}$ & $-141.6 \pm 56.9$ \\
\hline & 1732 & 1.52 & 1.55 & $\begin{array}{r}2.20 \\
-3.72\end{array}$ & $-260.1 \pm 15$ \\
\hline & 2372 & 1.33 & 1.31 & & \\
\hline Dep & h mean & -0.09 & -0.12 & -0.52 & $-218.6 \pm 22.8$ \\
\hline
\end{tabular}

integral time scale $\tau$, such as $N^{*}=t_{\text {tot }} / \tau$, where $t_{\text {tot }}$ is the total record length. Finally, the integral time scale $\tau$ is defined as

$$
\tau=\sum_{j=-M}^{M} C_{\mathrm{VV}}(j \Delta t) C_{\mathrm{TT}}(j \Delta t) \Delta t
$$

where $C_{\mathrm{VV}}$ and $C_{\mathrm{TT}}$ are the autocorrelation functions of $V^{\prime}$ and $T^{\prime}$, respectively. Nowlin et al. (1985) suggest that $M$ equals $20 \%$ of the number of observations. However, we have slightly modified the criterion by choosing a maximum time scale between the former using $M=$ $20 \%$ and that calculated with $M$ coinciding with the first zero crossing. Although these time scales do not differ much one from the other in general, this modification is intended to prevent any too short time scale which can be accidentally associated with large-amplitude oscillations of the autocorrelation functions about zero, if any.

Table 2 shows that the geographic and 90d-LP methods yield very similar results, while the shear method gives results quite different from the formers, both for the sign and magnitude of eddy fluxes. Nevertheless, most eddy flux estimates are not significantly different from zero at a $95 \%$ confidence level, whatever the method used, and only $25 \%$ of the time series are significant, on average. Longer time series of total length of about 3 years would be needed to establish the observed general weak correlations between $V^{\prime}$ and $T^{\prime}$ as being significant. Furthermore, there appear no systematic poleward eddy fluxes but the positive and negative fluxes are almost equally distributed, although the negative (or poleward) fluxes are slightly stronger, in general. We calculated the depth-averaged eddy fluxes separately for each method, using a layer thickness-weighted trapezoidal rule, which yielded negative but very small values ranging from -0.1 to $-0.5 \mathrm{~kW} \mathrm{~m}^{-2}$, with the greatest absolute value from the shear method. Of course, these values are not significant because we have simply averaged mostly insignificant individual estimates from different levels. The main message of this calculation is to show that the depth-mean eddy fluxes at the SACCF of our Kerguelen site are not only statistically not significant but also negligibly small. Our method-averaged, depth-mean poleward eddy flux of $0.3 \mathrm{~kW} \mathrm{~m}^{-2}$ is smaller by a factor of three than that in the southern Drake Passage and represents only $0.024 \mathrm{PW}$ if extrapolated over the circumpolar section (by multiplying 0.08 to take a circumpolar section of $4 \times 20000 \mathrm{~km}$ at $60^{\circ} \mathrm{S}$ into account). The latter value $(0.024 \mathrm{PW})$ is the smallest eddy flux in the ACC reported in the literature and accounts for about $6 \%$ of the oceanic heat loss to the atmosphere south of $60^{\circ} \mathrm{S}$, thus is too insignificant for further consideration.

\section{d. Estimates of poleward heat flux by the time-mean flow}

In shear coordinates, the cross-stream velocity component $V_{p}$ is predominantly negative (or poleward), except for the 1453-1950-db layer at M1 and in several time ranges in the layers above $1510 \mathrm{db}$ at M2 (Fig. 11). This means that the time-mean cross-stream velocity is significant and mostly directed poleward because of the dominant anticlockwise turning of velocity vectors with decreasing depth, as already mentioned. As the temperature is always positive in our case, the cross-stream total temperature flux $V_{p} T$ (not shown) largely mirrors the fluctuations of $V_{p}$ itself. The time-mean total heat flux $\left(41.4 \overline{V_{p} T}\left(\mathrm{~kW} \mathrm{~m}^{-2}\right)\right)$, which is practically determined by the product of mean velocity $\overline{V_{p}}$ and mean temperature $\bar{T}$, as $\overline{V_{p} T} \sim \overline{V_{p}} \bar{T}$ since $\overline{V_{p}^{\prime} T^{\prime}}$ has been shown to be small in the previous section, is shown in the last column of Table 2. The statistical significance of the mean at a $95 \%$ confidence level is tested by comparing with its standard error SE multiplied by 2 . The latter is estimated as $\mathrm{SE}=\mathrm{SD} / \sqrt{N^{*}}$, where $\mathrm{SD}$ is the standard deviation of $V_{p} T$ about its mean and $N^{*}$ is the effective degrees of freedom calculated using the autocorrelation function of $V_{p} T$, in place of $C_{\mathrm{VV}}$ and $C_{\mathrm{TT}}$ in (10).

As expected, all but for the near-bottom layer at M1 systematically present poleward mean heat fluxes, with their magnitude significantly greater than eddy heat fluxes by as much as two orders of magnitude. These are also statistically significant in most cases, except for two layers above $1510 \mathrm{db}$ at M2. A layer thickness-weighted vertical average is calculated by setting the statistically not significant flux values as zero, which gives 


\section{Cross-stream Velocity $(\mathrm{cm} / \mathrm{s})$}
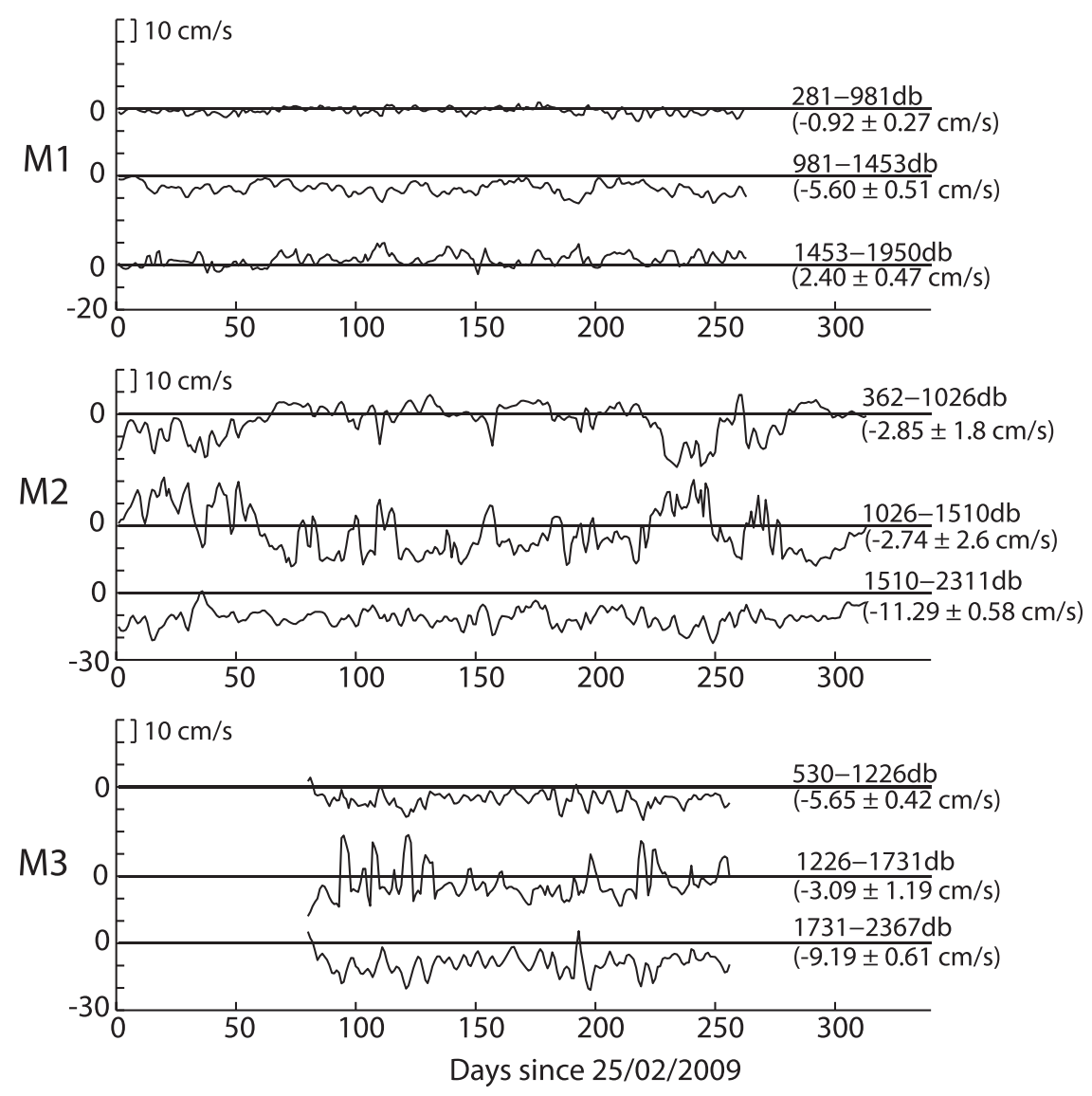

FIG. 11. Time series of the cross-stream velocity perpendicular to the thermal wind in shear coordinates on (top to bottom) the three moorings. Indicated on the right side of each velocity curve are the pressure range of two current meters from which the thermal wind is calculated and the record-length mean velocity \pm its standard error.

a depth-mean poleward heat flux of $219 \mathrm{~kW} \mathrm{~m}^{-2}$, with a $95 \%$ confidence range ( $\pm 2 \mathrm{SE})$ of 173 to $264 \mathrm{~kW} \mathrm{~m}^{-2}$, a value exceeding by more than one order of magnitude the highest poleward eddy flux ever observed in the ACC (Phillips and Rintoul 2000). Of course, we do not claim that such is a common feature in the ACC. We believe that our observations are rather atypical, taking part of some geographically limited situations in which a strong flow branch of the ACC is topographically steered through a sill to pass over a prominent submarine ridge, such as the Fawn Trough over the Kerguelen Plateau, inducing significant bottom upwelling and anticlockwise turning of currents with decreasing depth. Several sites similar to ours within the southern part of the ACC would contribute significantly to the required poleward heat flux in the subpolar region south of $60^{\circ} \mathrm{S}$. We will come back to this point later in the discussion section.

\section{e. Vertical velocity}

Based on the heat equation combined with the thermal wind Eq. (6), and assuming small mixing, one can derive a useful equation for calculating the vertical velocity $w$ from the current meter data (e.g., Bryden 1976; Lindstrom and Watts 1994; Phillips and Rintoul 2000), such as

$$
w=\frac{-\frac{\partial T}{\partial t}-\left(u \frac{\partial T}{\partial x}+v \frac{\partial T}{\partial y}\right)}{\frac{\partial \theta}{\partial z}}=\frac{-\frac{\partial T}{\partial t}-\frac{\rho_{0} f}{g \alpha_{e}}\left(u \frac{\partial v}{\partial z}-v \frac{\partial u}{\partial z}\right)}{\frac{\partial \theta}{\partial z}}
$$

where $\theta$ is potential temperature, and $\alpha_{e}$ is the effective thermal expansion coefficient defined in (5). The time series of $w$ is calculated at the pressure midway between 


\section{Vertical Velocity $(\mathrm{mm} / \mathrm{s})$}
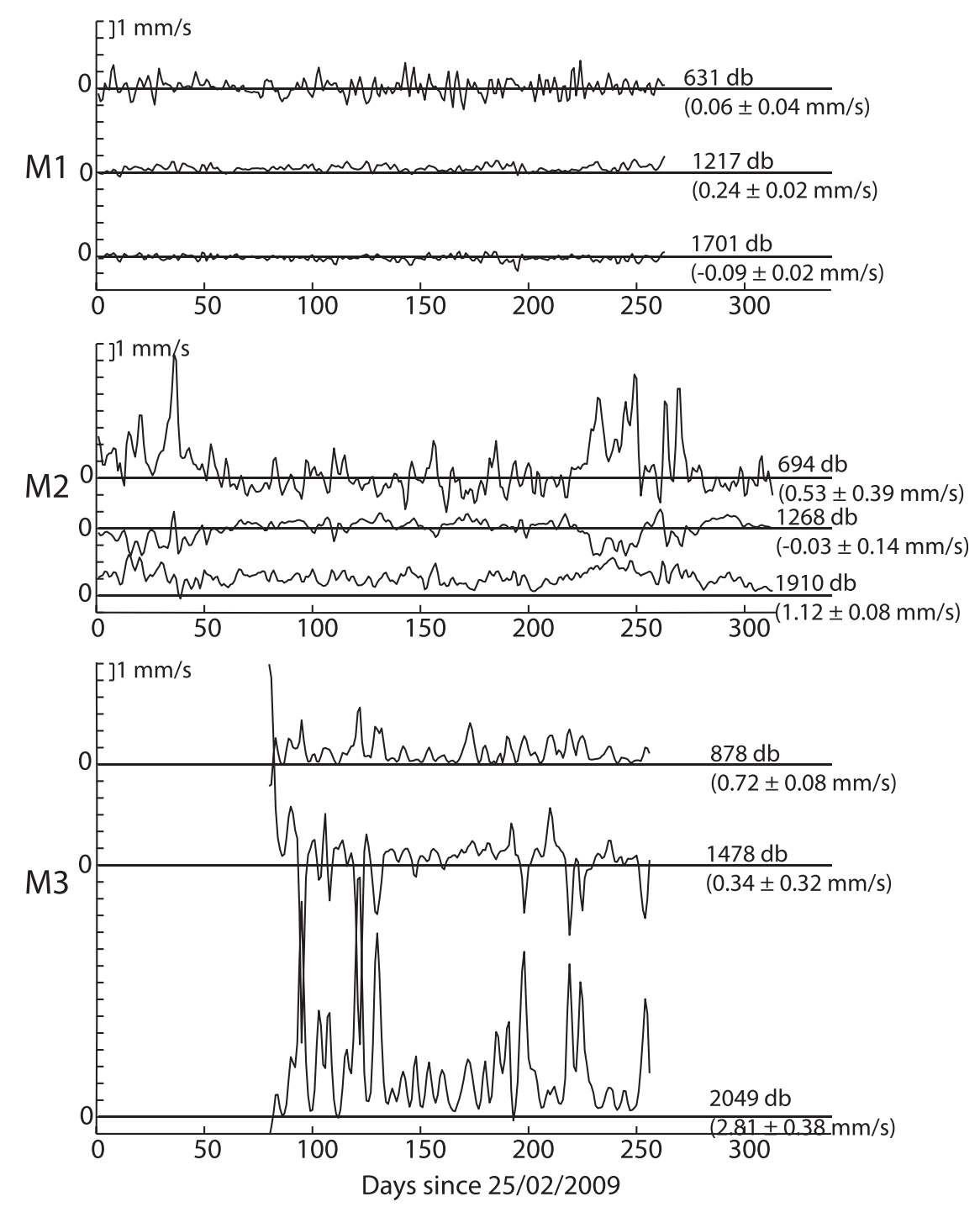

FIG. 12. As in Fig. 11, but for vertical velocity as calculated from (11). Indicated on the right side of each velocity curve is the mean pressure where the calculation is made.

adjacent current meters by using averages of data $(T, u$, and $v$ ) at adjacent current meters and taking constant $\alpha_{e}$ and $\partial \theta / \partial z$ values estimated from CTD data at each corresponding pressure; the vertical derivatives $(\partial u / \partial z$, $\partial v / \partial z)$ are approximated as centered finite differences using data at adjacent levels; temperature tendencies $(\partial T / \partial t)$ are computed using a second-order-centered finite difference scheme. The resulting time series at nine midpoint levels on the three moorings are shown in Fig. 12. Vertical velocities are highly variable owing to fluctuations on different time scales; however, there appears clear evidence of mean upwelling (positive $w$ ) at a number of levels, especially at M3. The strongest and most systematic upwelling is observed in the near-bottom layer at M3 (2049 db) and M2 (1910 db), with a significant time-mean vertical velocity of 2.8 and $1.1 \mathrm{~mm} \mathrm{~s}^{-1}$, respectively. This is followed by another important mean upwelling of $0.7 \mathrm{~mm} \mathrm{~s}^{-1}$ in the upper layer at M3 (878 db). Mooring M1 reveals the weakest vertical motions, with minor upwelling $\left(0.2 \mathrm{~mm} \mathrm{~s}^{-1}\right)$ at $1217 \mathrm{db}$ and downwelling $\left(-0.1 \mathrm{~mm} \mathrm{~s}^{-1}\right)$ in the nearbottom layer (1701 db), although they are significant at a $95 \%$ confidence level. In other layers of the moorings time-mean vertical velocities are all positive except for $1268 \mathrm{db}$ at M2, although they are not significant.

The vertical velocity is proportional to the two terms in the numerator of (11): the temperature tendency and the horizontal temperature advection. For 


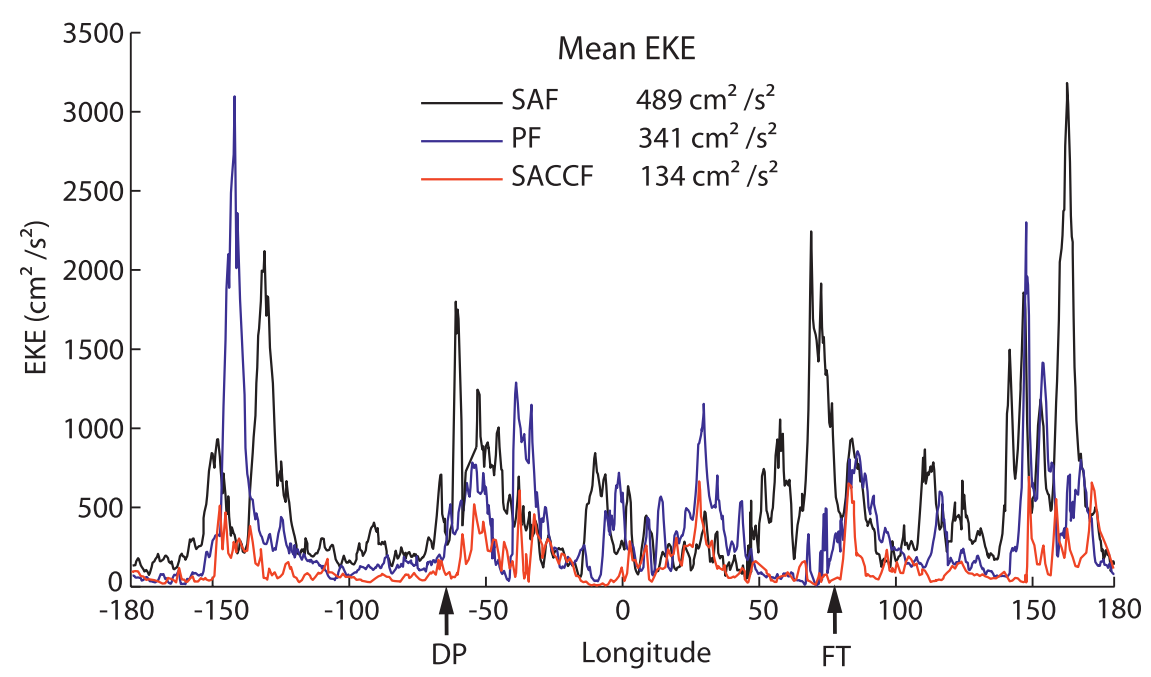

FIG. 13. Longitudinal distribution of satellite altimetry-derived eddy kinetic energy (EKE) (see Fig. 1) along the three major ACC fronts. The longitudinal positions of the Fawn Trough (FT) and Drake Passage (DP) at the SACCF are indicated.

the time-mean values, the former term is negligible compared to the latter term, which can be also written in polar coordinates as (Bryden 1976):

$$
-\frac{\rho_{0} f}{g \alpha_{e}}\left(u \frac{\partial v}{\partial z}-v \frac{\partial u}{\partial z}\right)=-\frac{\rho_{0} f}{g \alpha_{e}} R^{2} \frac{\partial \phi}{\partial z}
$$

where $R$ is the magnitude of the current, and $\phi$ is the angle of the current with respect to the east, defined positive for an anticlockwise turning. As the constant term, $-\rho_{0} f / g \alpha_{e}$ is positive in the Southern Hemisphere $(f<0)$, the sign of the mean vertical velocity depends on that of the turning of the current with depth $\partial \phi / \partial z$; upwelling is associated with anticlockwise turning and downwelling with clockwise turning with decreasing depth, as mentioned previously. This theoretical relationship is largely verified by our current meter data. For example, the strongest upwelling in the near-bottom layers at M3 and M2 can be compared with the strongest anticlockwise turning observed there (see Fig. 9), which is also associated with a significant poleward heat flux by the time-mean flow (see Table 2).

\section{Discussion}

We have shown that across the SACCF passing through the Fawn Trough over the Kerguelen Plateau, the poleward heat flux due to transient eddies is negligible $\left(0.3 \mathrm{~kW} \mathrm{~m}^{-2}\right)$ while that due to time-mean flow is abnormally large $\left(219 \mathrm{~kW} \mathrm{~m}^{-2}\right)$ and associated with strong upwelling and anticlockwise turning with decreasing depth. An important question is what implications these point observations have for the climate-relevant circumpolar heat flux, which is discussed below.

\section{a. Circumpolar implications of the observed poleward heat fluxes due to eddies}

It is well established that in the Southern Ocean the poleward eddy heat flux is closely related to the intensity of mesoscale eddy activity (e.g., Stammer 1998). As can be easily recognized from Fig. 1, the mesoscale eddy activity within the ACC, which is represented by the satellite altimetry-derived eddy kinetic energy (EKE), is not spatially homogeneous but shows great regional contrasts, with its maxima being found north of and along the northern flank of the ACC; EKE drops sharply poleward of the PF. The EKE maxima are also found immediately downstream of major submarine topographic features, in contrast to the very limited eddy activity over the features themselves. To place the Fawn Trough site within the context of the circumpolar EKE distribution, Fig. 13 shows the mean EKE along the three major ACC fronts. Here, we used the 9-yr (200210) mean $\operatorname{EKE} \overline{\left(u^{\prime 2}+v^{\prime 2}\right) / 2}$, calculated at each altimetric grid point using the 90d high-pass-filtered velocity anomalies $\left(u^{\prime}, v^{\prime}\right)$, before taking the nearest grid point values to the ACC fronts shown in Fig. 1. [Archiving, Validation, and Interpretation of Satellite Oceanographic data (AVISO) altimetric velocity data used are available online at http://www.aviso.oceanobs.com/en/ data/data-access services/ftp.html]. We see that EKE along the SACCF represents about one-fourth of that along the SAF in terms of the circumpolar average but only one tenth when comparing peak values. The Fawn 

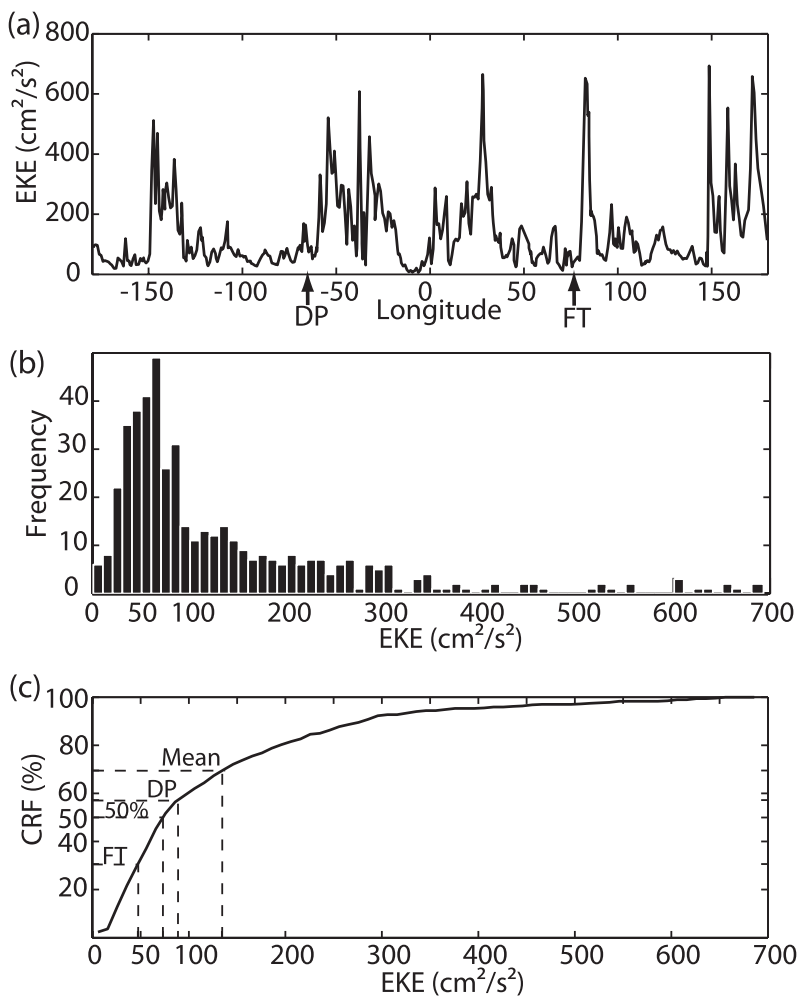

FIG. 14. (a) Longitudinal distribution of satellite altimetryderived EKE along the SACCF. (b) Frequency distribution and (c) the cumulative relative frequency (CRF) distribution of EKE at the SACCF. The EKE values corresponding to the circumpolar mean (mean), the median (50\%), Drake Passage (DP), and the Fawn Trough (FT) are indicated.

Trough is among the lowest EKE regions along the SACCF

The EKE distribution along the SACCF (Fig. 14a) is far from symmetric about the circumpolar mean but is highly skewed toward lower values (Fig. 14b). According to the cumulative frequency distribution of EKE (Fig. 14c), the southern Drake Passage studied by Nowlin et al. (1985) can be placed between the median and the arithmetic mean, while the Fawn Trough site is found well below the median. This may suggest that our Fawn Trough observations, when extrapolated around the entire circumpolar circle, will strongly underestimate the circumpolar poleward eddy heat flux, while the southern Drake Passage observations are much better representative of the latter flux. If so, the poleward eddy heat flux across the entire SACCF might not be much different from that extrapolated from the southern Drake Passage observations, which is found to yield only a minor contribution $(18 \%)$ to the oceanic heat loss to the atmosphere south of $60^{\circ} \mathrm{S}$ as already mentioned in the introduction. Such a minor eddy contribution as estimated from a few observations is in conflict with much larger estimates (by a factor of 2 to 3 ) in stream-following coordinates from high resolution models (Meijers et al. 2007; Treguier et al. 2007). It is difficult to judge whether the models overestimate the eddy heat transport, or whether the circumpolar extrapolation from a few local eddy estimates lacks realism. Further observations at different sites along the southern flank of the ACC are certainly needed for resolving the apparent conflict between observations and model studies.

\section{b. Circumpolar implications of the observed poleward heat fluxes due to the time-mean flow}

Consistent with Lindstrom et al. (1997) for the Northern Hemisphere case, we have shown that there is, in our Southern Ocean study area, a triple dynamical connection of the poleward heat flux, anticlockwise turning of currents with decreasing depth (clockwise in the Northern Hemisphere), and bottom upwelling. Our results are also consistent with the Southern Hemisphere ACC study of Phillips and Rintoul (2000) who used, like Lindstrom et al. (1997), the term veering (backing) for designating the anticyclonic (cyclonic) rotation with decreasing depth to illustrate the above triple relationship: upwelling-veering-warm advection or downwellingbacking-cold advection. Hence, to infer the circumpolar distribution of the poleward heat flux, we will first examine that of bottom velocity from the vertically integrated linearized vorticity balance, which is (Olbers et al. 2004; Hughes 2005)

$$
\beta V_{m}=J\left(p_{b}, H\right)+\nabla \times \boldsymbol{\tau},
$$

where $\beta=\partial f / \partial y$ is the northward derivative of the Coriolis parameter, $V_{m}\left(=\int \rho v d z\right)$ is the depth-integrated northward mass transport, $J$ represents the Jacobian operator, $p_{b}$ is bottom pressure, $H$ is bottom depth, and $\tau$ is surface wind stress. The Jacobian term represents the socalled bottom pressure torque (BPT), which is equivalent to the bottom vertical velocity $w_{b}$ (Wells and de Cuevas 1995; Olbers et al. 2004; Hughes 2005), since

$J\left(p_{b}, H\right)=\mathbf{k} \cdot\left(\nabla p_{b} \times \nabla H\right)=\rho f \mathbf{u}_{b} \cdot \nabla H=-\rho f w_{b}$,

where geostrophy ( $\left.\rho f \mathbf{u}_{b}=\mathbf{k} \times \nabla p_{b}\right)$ and the kinematic boundary condition $\left(\mathbf{u}_{b} \cdot \nabla H=-w_{b}\right)$ are used. In the Southern Hemisphere $(f<0)$, positive (negative) BPT means bottom upwelling (downwelling) and should be associated with anticlockwise (clockwise) turning with decreasing depth, thus poleward (equatorward) heat flux, as mentioned previously.

Based on the outputs of the Fine Resolution Antarctic Model (FRAM), Wells and de Cuevas (1995) analyzed the depth-integrated vorticity budget in the ACC, 

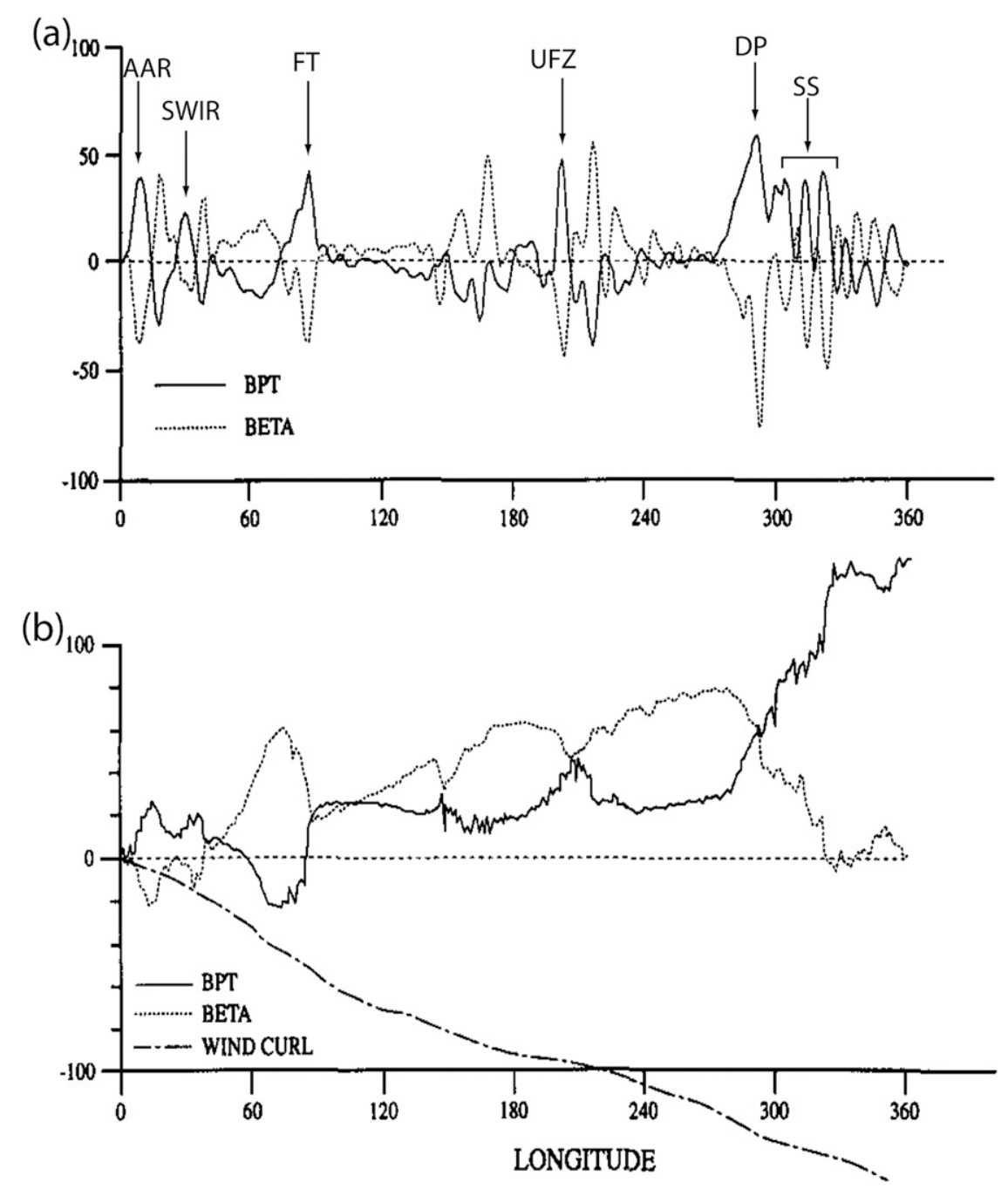

FIG. 15. (a) Longitudinal distribution of FRAM-derived two locally near-compensating vorticity terms [bottom pressure torque (BPT) and the $\beta$-term] on the southern flank of the ACC. Localized sites with significant positive BPT are indicated, such as Drake Passage (DP), the Scotia Sea (SS), the Fawn Trough (FT), the Udintsev Fracture Zone (UFZ), the AfricanAntarctic Ridge (AAR), and the Southwest Indian Ridge (SWIR). (b) Accumulation of three vorticity terms (BPT, $\beta$ term, wind stress curl) eastward from the Greenwich meridian. Adapted from Wells and de Cuevas (1995).

separately for its three branches subdivided by different ranges of the transport streamfunction: northern (10$70 \mathrm{~Sv})$, central (70-120 Sv), and southern (120-180 Sv) branches. We are interested here in the budget in the southern branch that covers the southern flank of the ACC including the SACCF. Figure 15, which is borrowed from Fig. 7 of Wells and de Cuevas (1995), shows the area-average vorticity budget in the southern branch as a function of longitude. Locally, the dominant balance is between BPT and the $\beta$ term (Fig. 15a), which tend to compensate each other, while the wind stress curl (not shown) is an order of magnitude smaller than the formers. Globally, or when integrated over the whole circumpolar longitudes (Fig. 15b), however, the $\beta$ term accumulates to zero and the dominant balance is between the BPT and the wind stress curl that is negative throughout the ACC. Although there is a tendency for cancellation of the BPT, hence yielding a reduced net contribution to the budget, the sense of this net BPT contribution is positive, counterbalancing the negative vorticity from the circumpolar wind stress curl. Significant positive BPT is confined to several very localized longitudes such as the Drake Passage-Scotia Sea region $\left(280^{\circ}-320^{\circ} \mathrm{E}\right)$, the Fawn Trough $\left(80^{\circ} \mathrm{E}\right)$, the Udintsev Fracture Zone $\left(200^{\circ} \mathrm{E}\right)$, the African-Antarctic Ridge $\left(10^{\circ} \mathrm{E}\right)$, and the Southwest Indian Ridge $\left(30^{\circ} \mathrm{E}\right)$. Among 
these, the Drake Passage-Scotia Sea region alone accounts for about half of the total positive BPT, while the Fawn Trough contributes to one sixth of the total. The total positive BPT is partially compensated by negative BPT from the rest of circumpolar regions to yield a reduced net positive BPT that amounts to about $60 \%$ of the total positive BPT.

If we apply this information from FRAM to our point observations in the Fawn Trough, we may estimate the order of magnitude of the circumpolar poleward heat flux due to the anticlockwise turning of time-mean flow. With a longitudinal extent of $5^{\circ}\left(\sim 300 \mathrm{~km}\right.$ at $\left.56^{\circ} \mathrm{S}\right)$ for the upslope side upstream of the Fawn Trough sill and a mean depth of $2500 \mathrm{~m}$, the local poleward heat transport from the Fawn Trough region using the observed mean flux range of $219 \pm 46 \mathrm{~kW} \mathrm{~m}^{-2}$ is 219000 $( \pm 46000) \times 300000 \times 2500=0.16( \pm 0.03)$ PW. Assuming the proportionality between the positive BPT and the poleward heat flux, as suggested by both the theory and observations, and considering the contribution of the Fawn Trough as much as one-sixth to the circumpolar total positive BPT, as well as $60 \%$ of the latter assigned to the circumpolar net positive BPT, the net circumpolar poleward heat transport is estimated as $0.16( \pm 0.03) \times 6 \times 0.6=0.58( \pm 0.11) \mathrm{PW}$. This range estimate of poleward heat flux $(0.47-0.69 \mathrm{PW})$ is consistent, albeit somewhat biased toward higher values, with the oceanic heat loss estimates south of $60^{\circ} \mathrm{S}$ of 0.2-0.65 PW (Large and Yeager 2009; Mazloff et al. 2010; Cerovečki et al. 2011; Gordon and Owens 1987; Hastenrath 1982). Note that air-sea heat fluxes especially in the Southern Ocean are subject to large uncertainty, varying greatly among different flux products (Cerovečki et al. 2011). For example, the recent flux product by Large and Yeager (2009) gives an oceanic heat loss south of $60^{\circ} \mathrm{S}$ of about $0.2 \mathrm{PW}$, which is significantly smaller than the heat loss diagnosed from the Southern Ocean State Estimate (SOSE) (Cerovečki et al. 2011). In fact, we have obtained a heat loss of $0.35 \mathrm{PW}$ south $60^{\circ} \mathrm{S}$ from the SOSE flux data communicated by M. Mazloff (2012, personal communication) (available at http://sose.ucsd.edu/sose_stateestimation_data_ 08.html). Nevertheless, our new method for estimating the poleward heat flux due to mean flow makes sense and appears to be useful, yielding a reasonable magnitude of the circumpolar poleward heat flux. Albeit encouraging, these results need further observations to be confirmed, especially at some anticipated "choke points" such as the Udintsev Fracture Zone and the Shackleton Fracture Zone upstream of Drake Passage. For this purpose, a French-Korean collaboration on board the recently-built Korean icebreaker Araon is under discussion to carry out in a near future similar measurements across these fracture zones as those made in the Fawn Trough.

Another concern may be whether the results from the FRAM model are robust compared to more recent models. Although it is difficult to compare directly with the FRAM results because of the unavailability of a streamwise integration of circumpolar vorticity balance, the Ocean Circulation and Climate Advanced Modeling (OCCAM) model, a more recent global model with higher resolutions and more realistic bathymetry than FRAM, shows a spatial distribution of BPT in the Southern Ocean similar to that of FRAM, with significant positive BPT being systematically observed over major topographic features (Hughes and de Cuevas 2001). This suggests that the relative contribution of positive BPT in the Fawn Trough region to the circumpolar net positive BPT, a key dynamical argument supporting the circumpolar extrapolation of our point observations of poleward heat flux by mean flow, would not be much different between the FRAM and OCCAM models, although a more quantitative comparison remains to be carried out.

Finally, it is worth emphasizing that our results do not support the paradigm of the dominant eddy heat flux across the ACC as suggested by de Szoeke and Levine (1981) who argued that there is no significant crossstream poleward heat flux by mean geostrophic flow. The main difficulty with the argument of these authors resides in the fact that their geostrophic velocities are calculated relative to a deep reference level where bottom currents are assumed to be zero, while it is the interaction of nonzero bottom current with sloping topography that generates upwelling and anticlockwise turning with decreasing depth. This is equivalent to assuming the equivalent barotropic structure of horizontal velocity even over a topographically constricted deep passage, which is not verified by the present study.

Acknowledgments. We are grateful to the captain and crew of the Marion Dufresne during the TRACK cruises, the DT/INSU for mooring instruments, and H. Le Goff and C. Rouault for the mooring, recovery, and preliminary treatment of current meter data. This work has benefited from the logistic or financial support from IPEV, CNES, and INSU. We thank H. Phillips for a mooring motion correction program and I. Durand for her contribution in data analysis and graphics. M. Mazloff kindly provided us with the SOSE-derived air-sea flux data.

\section{REFERENCES}

Bryden, H. L., 1976: Horizontal advection of temperature for lowfrequency motions. Deep-Sea Res., 23, 1165-1174. 
_ 1979: Poleward heat flux and conversion of available potential energy in Drake Passage. J. Mar. Res., 37, 1-22.

— , and R. A. Heath, 1985: Energic eddies at the northern edge of the Antarctic Circumpolar Current in the southwest Pacific. Prog. Oceanogr., 14, 65-87.

Cerovečki, I., L. D. Talley, and M. R. Mazloff, 2011: A comparison of Southern Ocean air-sea buoyancy flux from an ocean state estimate with five other products. J. Climate, 24, 6283-6306.

Cronin, M., and D. R. Watts, 1996: Eddy-mean flow interaction in the Gulf Stream at $68^{\circ} \mathrm{W}$. Part I: Eddy energetics. J. Phys. Oceanogr., 26, 2107-2131.

de Szoeke, R. A., and M. D. Levine, 1981: The advective flux of heat by mean geostrophic motions in the Southern Ocean. Deep-Sea Res., 28A, 1057-1085.

Ferrari, R., C. Provost, A. Renault, N. Sennéchael, N. Barré, Y.-H. Park, and J.-H. Lee, 2012: Circulation in Drake Passage revisited using new current time-series and satellite altimetry. J. Geophys. Res., 117, C12024, doi:10.1029/2012JC008264.

Gille, S. T., 2003: Float observations of the Southern Ocean. Part II: Eddy fluxes. J. Phys. Oceanogr., 33, 1182-1196.

Gordon, A. L., and W. B. Owens, 1987: Polar oceans. Rev. Geophys., 25, 227-233.

Hall, M. M., 1986: Horizontal and vertical structure of the Gulf Stream velocity field at $68^{\circ} \mathrm{W}$. J. Phys. Oceanogr., 16, 1814 1828.

— 1989: Velocity and transport structure of the Kuroshio Extension at $35^{\circ} \mathrm{N}, 152^{\circ}$ E. J. Geophys. Res., 94 (C10), 14 445-14 459.

Hastenrath, S., 1982: On meridional heat transport in the world ocean. J. Phys. Oceanogr., 12, 922-927.

Hogg, N. G., 1986: On the correction of temeperature and velocity time series for mooring motion. J. Atmos. Oceanic Technol., 3, 204-214.

_ 1991: Mooring motion corrections revisited. J. Atmos. Oceanic Technol., 8, 289-295.

Hughes, C. W., 2005: Nonlinear vorticity balance of the Antarctic Circumpolar Current. J. Geophys. Res., 110, C11008, doi:10.1029/ 2004JC002753.

_- and B. A. de Cuevas, 2001: Why western boundary currents in realistic oceans are inviscid: A link between form stress and bottom pressure torque. J. Phys. Oceanogr., 31, 2871-2885.

Killworth, P. D., 1992: An equivalent-barotropic mode in the fine resolution Antarctic model. J. Phys. Oceanogr., 22, 1379-1387.

—_, and C. W. Hughes, 2002: The Antarctic Circumpolar Current as a free equivalent-barotropic jet. J. Mar. Res., 60, 19-45.

Large, W. G., and S. G. Yeager, 2009: The global climatology of an interannually varying air-sea flux data set. Climate Dyn., 33, 341-364.

Lindstrom, S. S., and D. R. Watts, 1994: Vertical motion in the Gulf Stream near $68^{\circ}$ W. J. Phys. Oceanogr., 24, 2321-2333.

$\longrightarrow$, X. Qian, and D. R. Watts, 1997: Vertical motion in the Gulf Stream and its relation to meanders. J. Geophys. Res., 102, 8485-8503.

Mazloff, M. R., P. Heimbach, and C. Wunsch, 2010: An eddypermitting Southern Ocean state estimate. J. Phys. Oceanogr., 40, 880-898.

Meijers, A. J., N. L. Bindoff, and J. L. Roberts, 2007: On the total, mean, and eddy heat and freshwater transports in the Southern Hemisphere of a $1 / 8^{\circ} \times 1 / 9^{\circ}$ global ocean model. J. Phys. Oceanogr., 37, 277-295.
Nowlin, W. D., Jr., S. J. Worley, and T. Whitworth III, 1985: Methods for making point estimates of eddy heat flux as applied to the Antarctic Circumpolar Current. J. Geophys. Res., 90, 3305-3324

Olbers, D., D. Borowski, C. Völker, and J.-O. Wölff, 2004: The dynamical balance, transport and circulation of the Antarctic Circumpolar Current. Antarct. Sci., 16, 439-470.

Park, Y.-H., and L. Gambéroni, 1995: Large-scale circulation and its variability in the south Indian Ocean from TOPEX/ Poseidon altimetry. J. Geophys. Res., 100, 24 911-24 929.

_, _ , and E. Charriaud, 1993: Frontal structure, water masses and circulation in the Crozet Basin. J. Geophys. Res., 98, 12 361-12 385 .

—, E. Charriaud, and M. Fieux, 1998: Thermohaline structure of the Antarctic Surface Water/Winter Water in the Indian sector of the Southern Ocean. J. Mar. Syst., 17, 5-23.

—, F. Roquet, I. Durand, and J. L. Fuda, 2008: Large scale circulation over and around the Northern Kerguelen Plateau. Deep-Sea Res. II, 55, 566-581, doi:10.1016/j.dsr2.2007. 12.030 .

, F. Vivier, F. Roquet, and E. Kestenare, 2009: Direct observation of the ACC transport across the Kerguelen Plateau. Geophys. Res. Lett., 36, L18603, doi:10.1029/2009GL039617.

Peixoto, J. P., and A. H. Oort, 1992: Physics of Climate. American Institute of Physics, $520 \mathrm{pp}$.

Phillips, H. E., and S. R. Rintoul, 2000: Eddy variability and energetics from direct current measurements in the Antarctic Circumpolar Current south of Australia. J. Phys. Oceanogr., 30, 3050-3076

Rintoul, S. R., C. W. Hughes, and D. Olbers, 2001: The Antarctic Circumpolar Current system. Ocean Circulation and Climate, G. Siedler, J. Church, and J.Gould, Eds., Academic Press, 271302.

Roquet, F., Y.-H. Park, C. Guinet, F. Bailleul, and J. B. Charrassin, 2009: Observations of the Fawn Trough Current over the Kerguelen Plateau using the data from instrumented elephant seals. J. Mar. Syst., 78, 377-393.

Stammer, D., 1998: On eddy characteristics, eddy transport, and mean flow properties. J. Phys. Oceanogr., 28, 727-739.

Sun, C., and D. R. Watts, 2002: Heat flux carried by the Antarctic Circumpolar Current mean flow. J. Geophys. Res., 107, 3119, doi:10.1029/2001JC001187.

Treguier, A. M., M. England, S. R. Rintoul, G. Madec, J. Le Sommer, and J.-M. Molines, 2007: Southern Ocean overturning across streamlines in an edding simulation of the Antarctic Circumpolar Current. Ocean Sci. Discuss, 4, 653-698.

Vivier, F., and C. Provost, 1999: Direct velocity measurements in the Malvinas Current. J. Geophys. Res., 104, 21 08321103.

Volkov, D. L., L.-L. Fu, and T. Lee, 2010: Mechanisms of the meridional heat transport in the Southern Ocean. Ocean Dyn., 60, 791-801.

Walkden, G. J., K. J. Heywood, and D. P. Stevens, 2008: Eddy heat fluxes from direct current measurements of the Antarctic Polar Front in Shag Rocks Passage. Geophys. Res. Lett., 35, L06602, doi:10.1029/2007GL032767.

Wells, N. C., and B. A. de Cuevas, 1995: Depth-integrated vorticity budget of the Southern Ocean from a general circulation model. J. Phys. Oceanogr., 25, 2569-2582. 